\title{
Local-scale association of boreal birds with clearcuts does not translate to the landscape scale
}

\author{
by \\ CLAIRE E. FARRELL
}

A thesis submitted to the Faculty of Graduate and Postdoctoral Affairs in fulfillment of the requirements for the degree of Master of Science

in

Biology

Carleton University

Ottawa, Ontario

(C) 2018

Claire E. Farrell 


\section{Dedication}

This thesis is dedicated to my loving parents. To my mother Judy, without whom I could not have done this, and to my father Gary (1951-2010), without whom I did. 


\begin{abstract}
Many boreal forest birds, including the Common Nighthawk and Eastern Whip-poor-will, have shown recent steep population declines. Both species are known to use clearcuts as habitat locally; however this relationship has not been tested at a landscape-scale. In this study I addressed the question: Are landscapes with more clearcut associated with higher occupancy of Common Nighthawk and Eastern Whip-poor-will? I selected 49 recent clearcuts $(\leq 15$ years old) of similar size and placed acoustic recorders on their edges. I measured the proportion of recent clearcut within multiple spatial extents around each bird sample site. I also measured the proportion of open wetland in the landscapes as a covariate. Occurrence of neither species was significantly affected by the proportion of clearcut in the surrounding landscape, at any of the tested spatial extents. However, Common Nighthawk occupancy was lower in landscapes with higher proportions of older (11-15years old) clearcuts, and for both species occupancy was higher in landscapes with higher proportions of open wetland, significantly so for Eastern Whippoor-will. I propose that these species nest on clearcut edges because they seem to be similar to other open habitat like wetland edges. However, clearcuts may not offer the same level of insect prey supply as offered in the open wetlands and therefore do not act as similar foraging habitat. Thus, clearcut edges may act as ecological traps, attracting birds to nest in areas of lower habitat quality. I demonstrated that local-scale habitat associations do not necessarily scale up to a landscape-scale. My results suggest that the conservation of open wetlands will be important for persistence of these boreal bird species.
\end{abstract}




\section{Acknowledgements}

I would like to take this opportunity to thank my co-supervisors, Dr. Scott Wilson, Dr. Greg

Mitchell and Dr. Lenore Fahrig, who have not only acted as exceptional and supportive supervisors but have also been mentors and sources of inspiration to me throughout these years. I could not have asked for a more intelligent, invested, and optimistic group of scientists to work with. I would also like to thank Dr. Gabriel Blouin-Demers not only for taking the time be on my advisory committee, but also for his advice and helpful feedback throughout this process. I would also like to acknowledge the help of Dr. Steve Cooke and Dr. Stacey Robinson for their participation and input in the defence process.

My field work could not have been completed without my field assistant Amanda Findlay and her dedication to the project. I thank Dr. Rob Mackereth with the Centre for Northern Forest Ecosystem Research, not only for his logistical help, but also for his belief in my abilities as a researcher. Thank you to Vince Caruana and Mona Caruana for their donation of field lodgings and Christine Eberl for her help with recordings. I would like to thank Cameron Leitrants not only for his volunteer field work on this project, but also for his constant encouragement and support. Thank you in particular to Larry Watkins for his insight and help with the challenges of spatial data.

This project would not have been possible without the funding and support provided by Environment and Climate Change Canada. Lastly, I would like to thank wonderful family, Judy, Ian (Kayley), Eve (Mike), and many others, as well as my friends for their encouragement and endless faith in my ability to succeed. 


\section{Table of Contents}

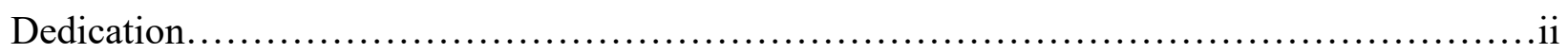

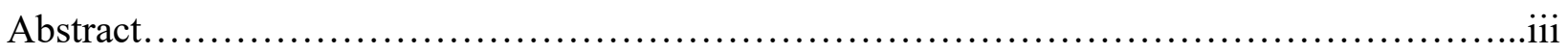

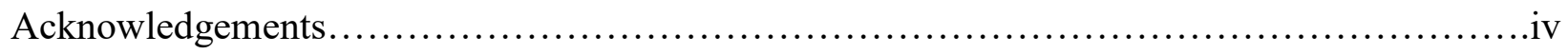

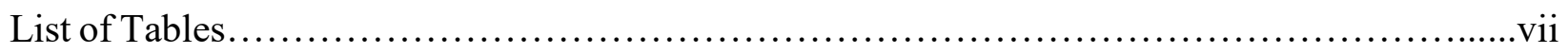

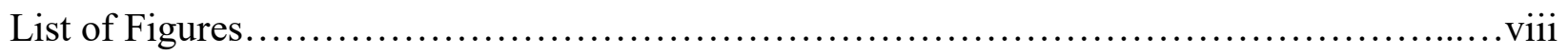

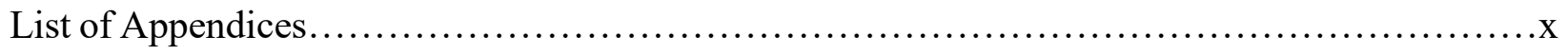

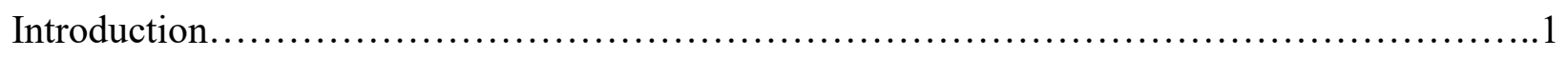

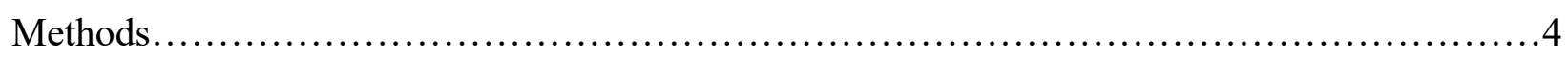

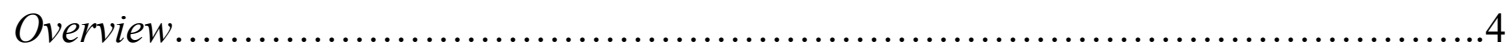

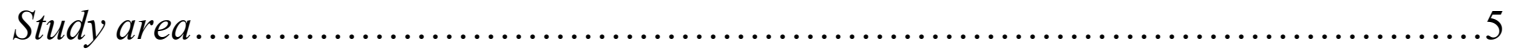

Site selection .................................................................... 5

Bird sampling methodology ..................................................

Spatial data and land cover analysis.............................................. 8

Other potentially confounding variables........................................ 9

Factors affecting detectability ...................................................10

Scale of effect of open wetland....................................................10

Effect of clearcutting on Common Nighthawk and Eastern Whip-poor-will...............11

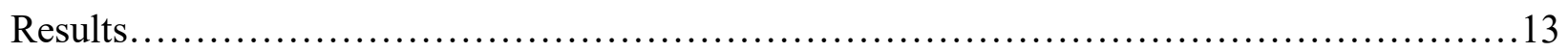

Factors Affecting Detectability ...............................................13

Scale of effect of proportion of open wetland.......................................... 14

Expectation 1: Landscapes with more clearcut have higher occupancy of Common Nighthawk and Eastern Whip-poor-will...........................................14

Expectation 2. Landscapes with more younger clearcuts have higher occupancy of Common Nighthawk and Eastern Whip-poor-will .....................................14

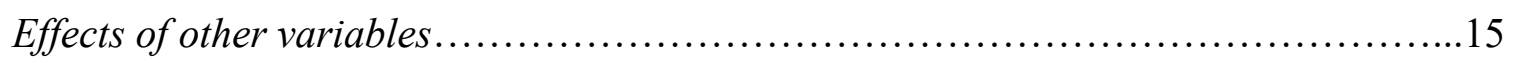

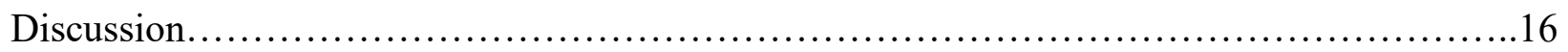


Responses to open wetland amount........................................ 19

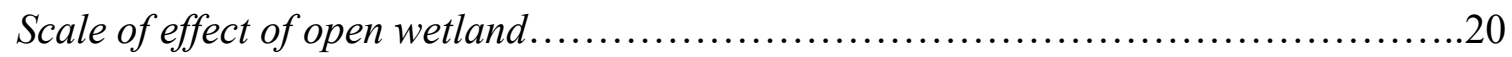

Local covariates...........................................................21

Species occupancy levels................................................22

Detectability: implications for sampling ....................................23

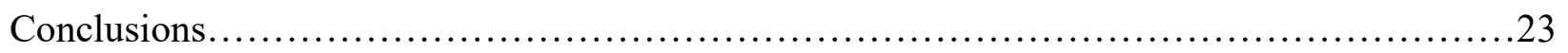

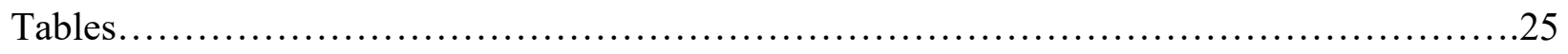

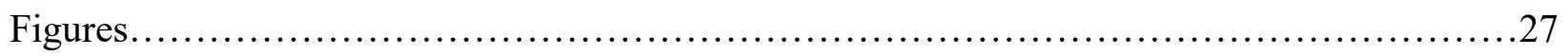

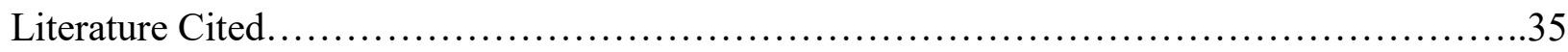

Appendices..................................................................44

Appendix I: Detectability Model Selection and Results............................44

Appendix II: Mean Occupancy of CONI and EWPW.............................49

Appendix III: Open Wetland Scale of Effect Analysis.............................50

Appendix IV: Total Clearcut Model Selection Analysis.................................51

Appendix V: Age-specific Clearcut Model Analysis.....................................55

Appendix VI: Farrell et al. (2017) Habitat Associations of CONI and EWPW............59

Appendix VII: Regional Effect on Proportion of Open Wetland.........................60

Appendix VIII: Diversity of Open Wetlands in Study Area .............................61 


\section{List of Tables}

Table 2.1. AICc table showing top models of total clearcut and age-specific occupancy model analysis for Common Nighthawk and Eastern Whip-poor-will at boreal forest sites in northwestern Ontario. Top detection variables for Common Nighthawk (time) and Eastern Whippoor-will (time+rain) were included in models but are not shown. $\triangle \mathrm{AICc}=$ change in Akaike's Information Criteria corrected for small sample size, wi $=$ Akaike weights, $\mathrm{K}=$ number of model parameters.

Table 3.1. Correlations among predictor spatial variables found among the best models (Table 2.1) measured with Spearman rank correlation values. The highest correlated variables are the proportion of wetland at $5 \mathrm{~km}$ and at $1.5 \mathrm{~km}$ and the proportion of total clearcut area and clearcuts 6-10 years old at $5 \mathrm{~km}$. 


\section{List of Figures}

Figure 2.1. Distribution of sampling sites for Common Nighthawk and Whip-poor-will across northwestern Ontario, northwest of Thunder Bay, Ontario, Canada. Each red dot represents one sampling site on a recent clearcut edge. General location of the study area in North America is represented as the red square in the inset image of North America (top right).

Figure 2.2. Age-based variation in clearcut patches found in Common Nighthawk and Eastern Whip-poor-will range in northwestern Ontario. Captions on the bottom right represent different ages of clearcuts and the regrowth associated with that age range $(0-5,6-10,11-15$, and 16-20 years old). The first three age ranges represent fairly open habitat whereas the older clearcuts in the 16-20 year old range demonstrate how regrowth can reduce open habitat.

Figure 2.3. Relationship between species occupancy of Eastern Whip-poor-will (EWPW) and Common Nighthawk (CONI) and the proportion of open wetland at different spatial scales evaluated using the change in Akaike's Information Criteria corrected for small sample size $(\triangle \mathrm{AICc})$. The lowest points in these curves represent the scale of effect where the relationship is strongest/variation in the response is best explained by the predictor. Significance is indicated with an $* *(p<0.05)$ or $* * *(p<0.01)$ at that spatial scale with $*$ indicating $\mathrm{p}<0.1$ but $>0.05$.

Figure 3.1. Sampling sites showing detection of Common Nighthawk (CONI) and Eastern Whip-poor-will (EWPW). Purple circles represent sampling sites with detection of both CONI and EWPW, blue circles represent sampling sites where only CONI were detected, red circles represent sampling sites where only EWPW were detected, and black circles represent sampling sites where neither CONI nor EWPW were detected. The inset image in the top left shows the distribution of sites in the study area northwest of Thunder Bay, Ontario, Canada. 
Figure 3.2. Model coefficient effect sizes for the influence of the proportion of open wetland at the scale of effect, the proportion of total recent ( $\leq 15$ years old) clearcut and the proportion of clearcut (11-15 years old) at their scales of effect. Coefficient values were taken from best model sets of both species (see Table 1). To demonstrate effects of all variables we report the coefficient value and $95 \%$ confidence intervals.

Figure 4.1. Two sample landscapes (5.0 km radius). The left image shows a landscape with recent clearcut area where both Common Nighthawk (CONI) and/or Eastern Whip-poor-will (EWPW) were not detected. The right image shows a landscape also with recent clearcut area, but with a much higher proportion of open wetland area, where both Common Nighthawk (CONI) and Eastern Whip-poor-will were detected. This comparison represents one of the main conclusions of our study; both Common Nighthawk and Eastern Whip-poor-will respond more strongly (positively) to open wetland area on a landscape-scale than to recent clearcut area. Thus, according to our findings, a landscape with a greater proportion of open wetland (right) has a higher probability of occupancy for Common Nighthawk and Eastern Whip-poor-will.

Figure 4.2. Presence (1) and absence (0) of Common Nighthawk (CONI) in northwestern Ontario, Canada, May-July 2017, as a function of proportion of open wetland within a radius of $1.5 \mathrm{~km}$ - the scale of effect. Shown are circles each representing one of 49 sampling sites, and a line of best fit.

Figure 4.3. Presence (1) and absence (0) of Eastern Whip-poor-will (EWPW) in northwestern Ontario, Canada, May-July 2017, as a function of proportion of open wetland within a radius of $5.0 \mathrm{~km}$ - the scale of effect. Shown are circles each representing one of 49 sampling sites, and a line of best fit. 


\section{List of Appendices}

Appendix I. Detectability model selection process and results

Appendix II. Mean occupancy of Common Nighthawk (CONI) and Eastern Whip-poor-will (EWPW)

Appendix III. Open wetland scale of effect analysis and results

Appendix IV. Total clearcut $(<15$ years old) model selection analysis

Appendix V. Age-classed clearcut model selection analysis

Appendix VI. Farrell et al. (2017) habitat associations of Common Nighthawk and Eastern

Whip-poor-will.

Appendix VII. Regional effect on proportion of open wetland

Appendix VIII. Diversity of open wetlands in study area 


\section{Introduction}

The Canadian boreal forest constitutes one of the largest continuous forests globally and is interspersed with openings created by lakes, wetlands, recent forest fires and forestry practices (NRCAN 2017). Faunal community diversity relies on heterogeneity in forest age and structure in the boreal forest (Hobson and Bayne 2000; Tews et al. 2004b; Fisher and Wilkinson 2005; Janssen et al., 2009). Historically, this heterogeneity was maintained by forest fires (Rowe and Scotter 1973; Hunter 1990). However, a combination of fire suppression and forestry has made clearcutting a dominant regime that creates this heterogeneity in the boreal forest. Large-scale clearcutting is thought to mimic forest fire's role in forest succession in terms of its scale and removal of mature forest (Hunter 1990; Hunter 1993; Haila et al. 1994; Delong and Tanner 1996; McRae et al. 2001). However, only $36 \%$ of clearcuts are left to regenerate naturally like fires do in Ontario. The majority of clearcuts are replanted and therefore regrow as same-age conifer stands unlike regenerating burned stands that regrow as deciduous or shrubby areas with a much higher plant diversity (Thompson and Pitt 2011).

The response of species to clearcutting is mixed (Smith 2012; Kellner 2016). Some research demonstrates initial negative effects of clearcutting on certain amphibian, bird, and cervid species (Bock and Lynch 1970; Davis 1977; Chubbs et al. 1993; Schulte and Niemi 1998; Simon et al. 2002; Fisher and Wilkinson 2005; Hins et al. 2009; Moorman et al. 2011; Kellner et al. 2016) including species at risk such as the boreal woodland caribou (Environment Canada 2012). However, other research shows that reptiles, large mammals like grizzly bears, and some species of birds can respond positively to different successional habitats created by aging clearcuts (Nielsen 2004; Wilson and Watts 2008; Becker et al. 2011; Hollander et al. 2011; Moorman et al. 2011; Zmihorski 2012; Tozer et al. 2014; Kellner et al. 2016; Farrell et al. 2017). It is 
important to understand how threatened species respond to clearcuts if one is to develop effective management plans for species at risk.

Two such species that are known to use clearcuts are Common Nighthawk and Eastern Whippoor-will (Morrison and Meslow 1983; Schieck et al. 2000; Cink 2002; Hagar et al. 2004; Wilson and Watts 2008; Brigham et al. 2011; Tozer et al. 2014; Akresh and King 2016; English et al. 2017; Farrell et al. 2017). Both migratory species are aerial insectivores that have shown marked declines in recent years (Nebel et al. 2010; Environment Canada 2015; Environment Canada 2016). Data from the North American Breeding Bird Survey indicate that across North America Common Nighthawk have declined by 4.2\% per year since 1968 (Downes et al. 2005), while Eastern Whip-poor-will have declined by 3.2\% per year since 1970 (Environment Canada 2015; Environment Canada, 2016). These declines represent population losses of over 75\% for both species over the past four decades. The mechanism for these dramatic declines is poorly understood (Environment Canada 2015; Environment Canada 2016). Both Common Nighthawk and Eastern Whip-poor-will are crepuscular aerial insectivores that nest in wooded areas, and forage for insects in open areas (Cink 2002; Kotliar et al. 2002; Russell et al. 2009; Brigham et al. 2011; Environment Canada 2015; Environment Canada 2016). Both species are known to select breeding sites that include nearby clearcuts and other types of open and early successional habitat, at least at the local scale (Morrison and Meslow 1983; Schieck et al. 2000; Cink 2002; Hagar et al. 2004; Wilson and Watts 2008; COSEWIC 2007; COSEWIC 2009; Brigham et al. 2011; Tozer et al. 2014; Akresh and King 2016; English et al. 2017; Farrell et al. 2017).

Early successional habitat created by clearcuts or by natural disturbances such as fires and insect outbreaks, is generally thought to have a "lifespan" of 0-15 years following the disturbance event (DeGraaf and Yamasaki 2003; Lorimer and White 2003). Age-specific habitat associations to 
clearcuts have been shown for Eastern Whip-poor-will for $<6$ year old clearcuts (Wilson and Watts 2008), 2-7 year old clearcuts (Akresh and King 2016), and 1-15 year old clearcuts (Tozer et al. 2014; Farrell et al. 2017) but they have also been shown to avoid nesting in clearcuts $<2$ years old (Akresh and King 2016). Age-specific associations for Common Nighthawk are less clear because studies considered "young" forest stands to be 20-30 years old or had low detectability of the species (Hutto et al. 1993; Stelfox 1995; Kirk and Hobson 2001). However, some age-specific associations of Common Nighthawk have been demonstrated for 1 year old clearcuts (Schieck et al. 2000), 4-5 year old clearcuts (Legrand et al. 2007), and 10-20 year old clearcuts (Hutto et al. 1993). Overall it seems that both species may be selecting clearcuts approximately $<10$ years old, with some exceptions.

Both forestry activities and management plans often target larger areas and therefore there is a need to understand how Common Nighthawk and Eastern Whip-poor-will respond to clearcutting at broader spatial scales than the local clearcut edge. Furthermore, it is important to investigate at what spatial extent these species respond to clearcutting (i.e. the scale of effect) to inform management and develop effective recovery strategies (Environment Canada 2015). Because both species show strong local habitat associations with clearcuts, it seems intuitive that their abundances and distributions could be increased by increasing the amount of clearcut area in their breeding range, particularly clearcuts that are $<10$ years old. However, this cannot be directly inferred from local-scale observations.

Scaling up ecological relationships from local to larger scales is known to be challenging (Allen and Hoekstra 1992; Wu 1999). As Tews et al. (2004a) noted in their large meta-analysis, ecological relationships must be measured at the appropriate spatial scale to make correct inferences. To date, two studies have evaluated landscape-scale habitat associations of Eastern 
Whip-poor-will and Common Nighthawk. However, neither study explicitly evaluated the effects of clearcut area. Thus, it is unknown how and at what scale clearcutting may affect these species in the boreal forest.

In this study I tested whether site occupancy of Common Nighthawk and Eastern Whip-poor-will increased with the amount of clearcut in the surrounding landscape. Based on studies at the individual scale I expected to find (1) Landscapes with more clearcut have higher occupancy of Common Nighthawk and Eastern Whip-poor-will and (2) Landscapes with more younger clearcuts have higher occupancy of both species.

\section{Methods}

Overview

To test these expectations I selected 49 bird sampling sites in the boreal forest of northwestern Ontario, Canada. I selected these sites to represent a wide range of total clearcut area within the surrounding landscapes of radius $5 \mathrm{~km}$ from the bird sampling sites. As I was specifically interested in the effects of clearcut area, I controlled for local habitat effects by ensuring sampling sites were as similar as possible. Additionally, to eliminate possible confounding effects of recently burned stands and open wetlands as known breeding habitat for the study species (Farrell et al. 2017), I selected sites that did not include any recently burned stand area within $5 \mathrm{~km}$ and included the proportion of open wetland within the landscapes as a covariate in my statistical models. I also accounted for potentially confounding variables at the local scale: dominant forest tree type, local clearcut patch size, local clearcut age, and red squirrel presence. I fit occupancy models for each species on the proportion of the surrounding landscape in 
clearcuts and, separately, the proportion the surrounding landscape in each age class of clearcuts, along with the potential confounding variables. I evaluated the effects of clearcut area (total and by age class) and wetland area at multiple spatial extents to identify the appropriate landscape extents for my species (Jackson and Fahrig 2015).

\section{Study area}

I conducted field work from May 31 through July 132017 in a remote study area north and west of Thunder Bay, Ontario, Canada spanning approximately $29,000 \mathrm{~km}^{2}$ (Fig. 2.1). This study area included both the Boreal Hardwood Transition and Boreal Softwood Shield bird conservation regions (Environment Canada 2014a, 2014b) and encompassed five forest management units; these are planning areas defined for the purposes of forest management (OMNRF 2018a). This region is comprised of mainly coniferous and mixedwood stands of black spruce (Picea mariana), white spruce (Picea glauca), jack pine (Pinus banksiana), balsam fir (Abies balsamea), tamarack (Larix laricina), eastern white cedar (Thuja occidentalis), and white birch (Betula papyrifera), with some maple species, red pine (Pinus resionsa), and eastern white pine (Pinus strobus) and trembling aspen (Populus tremuloides) (OMNRF 2018b). Forestry in this area targets both coniferous and deciduous trees (Greenmantle Forest Inc. 2017; Rainy Lake Tribal Resource Management Inc. 2017; Resolute FP Inc. 2017a; Resolute FP Inc. 2017b; RW Forestry Inc. 2018).

\section{Site selection}

I searched for accessible sampling sites on the edges of recent clearcuts ( $\leq 15$ years old). Potential sampling sites (approximately 69) were initially selected using recent clearcut spatial data (1997-2016) from Forest Resource Inventory data (OMNRF 2017). Forest Resource 
Inventory data are composed of spatial data and metadata pertaining to Ontario's forestry operations and overall land cover (OMNRF 2014). All potential sites were in forested areas free from urbanization, agricultural activity, or human settlements. Using the Google Maps Area Calculator Tool extension (DaftLogic), I then validated each site by (1) confirming the presence of a recent ( $\leq 15$ years old) clearcut patch, (2) ensuring patches were of similar size and (3) confirming that each sampling site was on its own unique clearcut.

To ensure independence of my sample sites I selected sites with at least $1.4 \mathrm{~km}$ to the next nearest sample site (maximum $16 \mathrm{~km}$, mean $3.8 \mathrm{~km}$ ). These distances are farther than known foraging distances of Eastern Whip-poor-will (0.13-0.31 km; Cink, 2002 and Rand, 2014) and Common Nighthawk (0.3-0.37 km; Brigham and Fenton 1991; Armstrong 1965). My final 49 sampling sites were also on the edges of clearcut patches averaging 95 ha each (ranging 12-364 ha) and $\geq$ $100 \mathrm{~m}$ from the access road (Fig. 2.1).

\section{Bird sampling methodology}

To measure occupancy of Common Nighthawk and Eastern Whip-poor-will, I placed acoustic bird song recorders (SM2 and SM4 models, Wildlife Acoustics Inc., Maynard, MA) on live, mature trees at the edges of clearcut patches at breast height, no more than $5 \mathrm{~m}$ from the forest edge from May 31 through July 13 2017. I placed one recorder per site, which sampled for approximately one week. Because of the size of my study area (Fig. 2.1), and the distance needed to travel across it, it was not possible to deploy all recorders simultaneously. I instead rotated recorders. I placed as many recorders as was logistically feasible each week. In the following week, I then returned to sites with recorders, collected the units and deployed them at new sites. This process was continued until all 49 sites had been sampled for approximately seven nights 
each. To account for the possible effect of non-simultaneous sampling, I included date (day-ofyear) as a detection covariate

Though I sampled for approximately seven nights at each site, only four nights were actually used in the analysis. This sampling procedure gave me greater flexibility to select four nights of optimal sampling within the seven day period over which recorders were at the site (i.e. nights without inclement weather such as rain, wind or thunder that influenced my ability to detect the species). If inclement weather was present in more than $50 \%$ of a single night's samples, that night was excluded in its entirety, and the next chronological night was used.

As both species call at night, recordings were made throughout each of the nights sampled. On a given sampling night, the recorder was programmed to turn on for seven 10-minute periods during the night: (1) one hour before sunset, (2) at sunset, (3) one hour after sunset, (4) two hour after sunset, (5) two hours before sunrise, (6) one hour before sunrise, and (7) at sunrise. The Common Nighthawk's "peent" and "boom" calls and Eastern Whip-poor-will's “whip-poorwill" song were used to determine the presence of the species. Detection for both species was determined by listening to the first five minutes of each 10 minute sample for the first four nights during which there was no inclement weather (high winds, rain, thunder). I note however that an individual recording (10 minute recording) on a given night may have had rain, wind, or thunder present, but not have been excluded from analysis (i.e. the night had less than $50 \%$ recordings with inclement weather and was therefore included in the analysis). To account for the effect of inclement weather on a single 10 minute recording, I included wind, rain, and thunder as detection covariates. 


\section{Spatial data and land cover analysis}

I measured my spatial variables - clearcut area and wetland area in the landscape surrounding each sampling site - at multiple spatial extents to determine at what extent they may affect occupancy. I used land cover data from the Forest Resource Inventory, an Ontario Government open access spatial dataset that divides Ontario into detailed spatial layers including different cover types (e.g. open water, various wetland types, grassland, etc.) as well as detailed forestry data (type and age of all historical forestry activity). I extracted open wetland and clearcut spatial data.

To test my first expectation (Landscapes with more clearcut have higher occupancy of Common Nighthawk and Eastern Whip-poor-will), I computed the proportion of the landscape in recent clearcut $\leq 15$ years old (clearcut area $\left(\mathrm{km}^{2}\right) /$ total landscape area $\left(\mathrm{km}^{2}\right)$ ), for all 10 spatial scales (0.5-5.0 km in increments of $0.5 \mathrm{~km}$ ). To test my second expectation (Landscapes with more younger clearcuts have higher occupancy of both species), I divided all clearcuts into four age classes $(0-5,6-10,11-15,16-20$ years old; Fig. 2.2) using the age metadata from the Forest Resource Inventory. I then calculated the proportion of the each age class in the landscape (total area of clearcut in a given age class $\left(\mathrm{km}^{2}\right) /$ total landscape area $\left.\left(\mathrm{km}^{2}\right)\right)$, for all 10 spatial scales. I included the 16-20 year old age class to test my assumption that clearcuts beyond 15 years old are not habitat for either species.

As mentioned previously, I controlled for possible confounding effects of the area of recent burned stands on Common Nighthawk and Eastern Whip-poor-will occurrence by ensuring that my selected landscapes did not contain any recent ( $\leq 15$ years old) burned stands, using forest fire record maps (OMNRF 2015). I could not do the same for open wetland area because of the 
high concentration of wetlands in my study area ( $6.6 \%$ of study area). To mitigate the potential confounding effects of open wetlands, I selected landscapes with a relatively small range of open wetland proportion (0.01-0.17 at $5 \mathrm{~km}$ radius) and I also computed the proportion of open wetland (open wetland area $\left(\mathrm{km}^{2}\right) /$ total landscape area $\left.\left(\mathrm{km}^{2}\right)\right)$ for all 10 spatial scales $(0.5-5.0$ $\mathrm{km}$, increments of $0.5 \mathrm{~km}$ ). I included this as a covariate in my occupancy models.

\section{Other potentially confounding variables}

In addition to my landscape variables - proportion recent clearcut, four age-classes of clearcut proportion, and proportion open wetland - I also accounted for several local variables that could affect clearcut occupancy by the two species. To account for differences in nesting condition of the forest floor surrounding the clearcut where these species could be nesting, I included the forest type within a radius of $100 \mathrm{~m}$ of the acoustic recorder (coniferous, mixedwood coniferous and deciduous, or deciduous) as my first local variable. Previous work in the study area found that the presence of the other species (either Common Nighthawk or Eastern Whip-poor-will) can significantly influence the occupancy of these two species (Farrell et al 2017). To account for this effect I included whether or not the other species was detected at that sampling site as a binomial variable $(1=$ yes, $0=$ no), Furthermore, research has demonstrated that bird species can respond differently to patch size in forested landscapes (Lehnen and Rodewald 2009). To account for the possible effect of size of local patch, I included the area $\left(\mathrm{km}^{2}\right)$ of the sampling site clearcut (using the GoogleMaps extension from DaftLogic). As noted in the introduction, some age-specific associations of clearcuts with these species have been seen (Legrand et al 2007; Akresh and King 2016). To account for the effect of the age of clearcut at my sampling site clearcut, I included age of clearcut at the site as a variable (based on the Forest Resource Inventory data). 
Lastly, I wanted to include an indicator of predation at the local scale if in fact that would affect occupancy. So, I included the detection of red squirrel as a covariate $(1=$ observed, $0=$ not observed on my acoustic recordings) to account for a possible effect of predation pressure on local occupancy (Degregorio et al. 2016; Reitsma et al. 1990). Because red squirrels are largely diurnal, I recorded an additional 10 minutes, three hours after sunrise each day, to obtain daytime estimates of red squirrels (Bayne and Hobson 2000). Both alarm and bark calls of the red squirrel were used to determine the presence of the species on a given recording.

\section{Factors affecting detectability}

I accounted for five variables that could have influenced the detectability of the two bird species (Farrell et al. 2017; Mills 1986; Wilson and Watts 2006): (1) day-of-year of the recording, with May 31 = day one, (2) time of sampling as a categorical variable (one hr. before sunset, at sunset, one and two hr. after sunset, two and one hr. before sunrise, at sunrise), (3) rain as a binomial variable (= 1 if it occurred during the recording period), (4) wind as a binomial variable (= 1 if wind noise occurred during the sample), and (5) lunar illumination (=\% illumination determined using the midpoint latitude/longitude of the study area and Hoffman MoonCalc tool (Hoffman 2018)). The fifth detection variable, lunar illumination, was included because detection of the Eastern Whip-poor-will is significantly higher with more moonlight (Wilson and Watts 2006).

\section{Scale of effect of open wetland}

To evaluate the effects of my landscape variables - proportion of the landscape in recent clearcuts, in each age class of clearcuts, and in open wetlands - I needed to determine the appropriate spatial extent for each (the scale of effect). Although I could have made an educated guess using information on movement ranges of the species, this type of estimate has been 
shown to be highly inaccurate (Jackson and Fahrig 2015). Therefore, I conducted multi-scale analyses (Brennan et al. 2002) to empirically estimate the scales of effect.

Because I considered open wetland to be a potentially confounding variable, I conducted the multi-scale analysis for open wetland as a preliminary analysis. I then entered the proportion of open wetland at its scale of effect as a covariate in the main analyses that focussed on testing my expectations about the effects of clearcut proportion. Before estimating the scale of effect for open wetland I first ran a preliminary model selection (see Appendix I) to determine which detection variable(s) affected the occupancy of each of the two species. For each species I then ran 10 occupancy models, one for wetland proportion at each of the 10 scales. I included the top detection model parameters from the preliminary analysis in each of these 10 models. I computed the adjusted AIC value for smaller sample sizes (AICc, Hurvich and Tsai 1989; Barton 2018) and used the change in AICc ( $\triangle \mathrm{AICc})$ to graphically represent the models (Fig. 2.3). The scale of effect for open wetland was then selected for the scale at which the AICc was lowest (Appendix III).

\section{Effect of clearcutting on Common Nighthawk and Eastern Whip-poor-will}

I conducted two sets of analyses: one for the effect of proportion of total recent clearcuts $(\leq 15$ years old) on each species (for expectation 1), and one for the effect of each age-class of clearcuts on each species (for expectation 2). Each set was conducted at each of the 10 spatial extents to determine the scale of effect for the clearcut variables. I used single season site occupancy models to test for the effect of clearcuts on my focal species while accounting for detection probability (MacKenzie et al. 2002) and potentially confounding variables. 
Support for my expectations was informed by model selection along with the effect size and confidence intervals for parameter estimates. Models were ranked using Akaike's Information Criterion corrected for a small sample size (AICc), and the $\triangle \mathrm{AICc}$ values and Akaike weights (wi) were used to infer support for each of the candidate models (Hurvich and Tsai 1989; Burnham and Anderson 2002; Barton 2018). As described in the previous section, my process for identifying top candidate models began by first running a set of models that only included variables influencing detection probability of each species (Appendix I). I then included influential variables in the suite of models to test my two expectations.

To test my first expectation, I ran separate models including the proportion of total recent clearcuts ( $\leq 15$ years old) at each of my 10 different spatial scales. I also included my other explanatory covariates (e.g. proportion open wetland area, red squirrel presence etc.) by themselves and in various combinations with each other and clearcut proportion to determine the top model again based on the lowest AICc value (Appendix IV). I report model coefficients, AICc values and Akaike's weight from the top models of this analysis (Table 2.1).

To test my second expectation, I conducted a set of analyses using the four variables that represented the proportions of the four age classes of clearcuts. I first conducted a series of 10 models, one for each spatial extent, to determine the scale of effect of these clearcut variables. Each model included all four variables measuring the proportion of the landscape in each of the four clearcut age classes, measured at that spatial scale (i.e. clearcuts 0-5 + clearcuts 6-10+ cleacuts 11-15 + clearcuts 16-20 years old, all at one scale). I selected the model at the scale of effect (the model with the lowest AICc) and then added my other explanatory covariates (e.g. proportion open wetland area, red squirrel presence etc.) by themselves and in various combinations with each other to determine the top global model using the lowest AICc value 
again. I then removed terms from the top global model until only influential variables remained in my final top model (Table 2.1, Appendix V). I report model coefficients, AICc values and Akaike's weight from the top and best models of this analysis (Table 2.1).

For Common Nighthawk and Eastern Whip-poor-will respectively I examined my model's fit by using a parametric bootstrap test on the most parameterized model from the total clearcut analysis. I simulated 200 data sets and refit the model to the data using a chi-squared fit statistic. This allowed me to compare how simulated data, made from my model, differed from my observed data. A well fit model should not be extremely different relative to the values from the bootstrapped distribution. I used $p>0.05$ to indicate an adequate fit (Fiske and Chandler 2014). The observed values from model for Common Nighthawk and Eastern Whip-poor-will did not different significantly from the simulated bootstrapped distribution $(\mathrm{p}=0.244$ and $\mathrm{p}=0.239)$.

\section{Results}

I detected Common Nighthawk at 33/49 sampling sites and Eastern Whip-poor-will at 14/49 sampling sites (Fig. 3.1). The mean probability of detection for Common Nighthawk was $0.29 \pm$ 0.01 with a probability of occupancy of $0.67 \pm 0.07$. The mean probability of detection for Eastern Whip-poor-will was $0.27 \pm 0.02$ with a mean probability of occupancy of $0.29 \pm 06$.

Correlations among the predictor variables are shown in Table 3.1. In general, the spatial predictor variables in my best models (Table 2.1) were not highly correlated. However, there were two sets of variables that showed substantial correlation to each other. The variables most correlated with each other were the proportion of open wetland at $5 \mathrm{~km}$ and $1.5 \mathrm{~km}$ followed by the proportion of total clearcut and clearcuts 6-10 years old at $5 \mathrm{~km}$.

Factors affecting detectability 
Detectability of both species varied most with the time of day ("time") of the sample (Table 2.1, Appendix I). Detectability for Common Nighthawk was significantly higher two hours after sunset and at sunrise and significantly lower an hour before sunset and two hours before sunrise (Appendix I). Detectability for Eastern Whip-poor-will was significantly higher one hour before sunrise and significantly lower during sunset. Eastern Whip-poor-will detectability was also negatively influenced by the presence of rain. Detectability of neither species was significantly related to lunar illumination (\%) (Appendix I).

Scale of effect of proportion open wetland

The scale of effect for the proportion of the landscape in open wetland was $1.5 \mathrm{~km}$ for Common Nighthawk and $5.0 \mathrm{~km}$ for Eastern Whip-poor-will respectively (Fig. 2.3, Appendix III).

Expectation 1: Landscapes with more clearcut have higher occupancy of Common Nighthawk and Eastern Whip-poor-will

The scale of effect for total recent clearcut ( $\leq 15$ years old) was $5 \mathrm{~km}$ for Common Nighthawk and Eastern Whip-poor-will (Table 2.1, Appendix IV). However, total recent clearcut was not included in the top occupancy model for either species (Fig. 3.2, Table 2.1). The second best model for Eastern Whip-poor-will and third best model for Common Nighthawk did include the proportion of total recent clearcut at a $5.0 \mathrm{~km}$ scale, with a positive effect (Table 2.1).

Expectation 2. Landscapes with more younger clearcuts have higher occupancy

The scale of effect for the models including variables for the separate clearcut age classes was $0.5 \mathrm{~km}$ for Common Nighthawk and $5.0 \mathrm{~km}$ for Eastern Whip-poor-will. However, the effects of the clearcut variables were not strong. For Eastern Whip-poor-will none of the four age-classes 
of clearcuts were included in the top model (Fig. 3.2, Table 2.1, Appendix V). For Common Nighthawk the top model included clearcuts $11-15$ years old at a $0.5 \mathrm{~km}$ scale, but with a negative effect (Fig. 3.2, Table 2.1, Appendix.V). None of the other clearcut variables showed a significant influence on occupancy of my species.

\section{Effects of other variables}

Although my results did not support my expectations for the role of landscape-scale clearcut amount on Common Nighthawk and Eastern Whip-poor-will occupancy, other variables were included in the top models. Common Nighthawk occupancy was significantly higher in clearcuts abutted by coniferous mature forest $(\mathrm{p}<0.001)$ compared to those with deciduous and mixedwood. The second and third best models also included a positive effect of the proportion of open wetland at $1.5 \mathrm{~km}$, and clearcut at $5.0 \mathrm{~km}$, but neither of these was significant (Table 2.1, Appendix IV). Eastern Whip-poor-will showed a positive, significant relationship to proportion of open wetland at $5.0 \mathrm{~km}$ (Table 2.1, Appendix IV) while all other variables were not significant.

In the models with separate variables for the different clearcut age classes, the top model for Eastern Whip-poor-will only included open wetland proportion, which had a positive effect on occupancy. The top model for Common Nighthawk included the proportion of clearcuts 11-15 years old and showed a negative effect of this age of clearcuts on the species (Fig. 3.2). I detected red squirrels at 28/49 sites but neither species showed an effect of red squirrel presence on occupancy probability nor was either species influenced by the presence of the other species. 


\section{Discussion}

Overall, I found no support for either of my expectations of higher occupancy of both species in landscapes with more clearcuts and younger clearcuts. Top models did not include measures of total clearcut. Although clearcuts 11-15 years old were in the top model for Common Nighthawk, the relationship was negative, not positive. Despite the lack of support for my expectations about clearcut area, I did find effects of open wetland amount on these species. Eastern Whip-poor-will occupancy was significantly higher in landscapes with more open wetland area. Common Nighthawk also showed a positive association (Fig 4.1., Fig. 4.2., Fig. 4.3), though the relationship was not significant in the final model. It is interesting that I still observed these strong effects of wetland amount despite selecting sites with limited variability in wetland amount in order to isolate the effects of clearcut amount on the two species. Together, the lack of a landscape-scale effect of clearcut amount combined with the positive effect of open wetland amount has important implications for management of these species (below).

The lack of effect of clearcut area was unexpected given the documented habitat associations of both species. Common Nighthawk and Eastern Whip-poor-will are known to select nesting sites that include nearby clearcuts (Morrison and Meslow 1983; Schieck et al. 2000; Cink 2002; Hagar et al. 2004; Wilson and Watts 2008; Brigham et al. 2011; Tozer et al. 2014; Akresh and King 2016; English et al. 2017; Farrell et al. 2017) and to select clearcuts $<10$ years old at the local scale (Schieck et al. 2000; Legrand et al. 2007; Wilson and Watts 2008; Tozer et al. 2014; Akresh and King, 2016; Farrell et al. 2017). My results therefore imply that I cannot extrapolate habitat use at the local scale to habitat importance at a landscape scale, at least for these two species. I suggest this mismatch between local and landscape scales indicates that while clearcut edges do provide nesting habitat for these species (Tyler 1940; Morrison and Meslow 1983; 
Schieck et al. 2000; Cink 2002; Hagar et al. 2004; Wilson and Watts 2008; Brigham et al. 2011; Tozer et al. 2014; Environment Canada 2015; Akresh and King 2016; English et al. 2017; Farrell et al. 2017), they may not provide significant foraging opportunities in comparison to other open habitats such as open wetlands. This idea is supported by Alexander and Cresswell (1990) who found that European nightjars, a close relative of Common Nighthawk and Eastern Whip-poorwill, foraged significantly less in clearcuts compared to other habitat types. Furthermore, they found that despite the small amount of wetland in their study area, the species foraged in wetland areas 3-5 times more frequently than expected (Alexander and Cresswell, 1990).

I postulate that clearcuts may be lower-quality foraging habitat than wetlands for these species because of lower insect densities, possibly due to clearcutting practices such as herbicide application. Research has shown clearcuts can have smaller insect communities than burned stands (Chaundry-Smart et al. 2012), and selectively harvested sites (Duguay et al. 2000). Furthermore, following the application of herbicides insect abundances can be significantly reduced (Cobb et al. 2006; Stark et al. 2012). Herbicide application is a part of clearcutting and occurs in my study area. (Greenmantle Forest Inc. 2017; Rainy Lake Tribal Resource Management Inc. 2017; Resolute FP Inc. 2017a; Resolute FP Inc. 2017b; RW Forestry Inc. 2018). Herbicides reduce lepidopteran (Cobb et al. 2006) and coleopteran species (Iglay et al. 2012; Stark et al. 2012), which are important prey for Common Nighthawk (Todd et al. 1998; Knight et al 2018) and Eastern Whip-poor-will (Garlapow 2007; English et al. 2017).

The lack of a relationship between the proportion of clearcutting in a landscape and the occupancy of my focal species does not necessarily indicate that clearcuts are benign. Both species select clearcut landscapes for nesting, but occupancy may be lower than expected for two reasons. First, landscapes with high clearcut cover may appear similar to landscapes with a high 
cover of natural openings (e.g. open wetland and recent burned stands), regardless of whether food supply differs among them. If either the amount or quality of the insect prey base is lower in clearcuts compared to natural open habitats, it would suggest that clearcuts may act as ecological traps. There is some indirect evidence of this potential effect from work on other bird species. Avian reproductive success in clearcuts has been shown to be low compared to other open habitat types (Duguay et al. 2000; Shin and Yoo 2016) and specifically lower than in wetlands for ovenbirds (Streby and Andersen 2013). Hollander et al (2011) demonstrated that nest success and offspring quality of the red-backed shrike (which preferentially nests in clearcuts) were lower in clearcuts compared to agricultural nesting sites. The possibility of similar effects on Common Nighthawk and Eastern Whip-poor-will needs to be investigated further.

I secondly postulate that a reason for lower occupancy in clearcut landscapes may be due to road mortality. Landscapes with high clearcut cover also have high logging road density. It is possible that individuals of both species select landscapes with higher amounts of clearcutting but also experience higher mortality resulting in lower densities (Bishop and Brogan 2013; Jack et al. 2015). Both Common Nighthawk and Eastern Whip-poor-will are known to use roads, including logging roads, found in their breeding habitat (COSEWIC 2007; COSEWIC 2009), and experience road mortality as a result (Poulin et al. 1996; Bender and Brigham 1995; OMNRF 2018c). However, Eastern Whip-poor-will often at night sit on gravel roads or road shoulders (Cink 2002), which makes then more vulnerable to vehicle collisions (Jackson 2003). English et al. (2017) even found that Eastern Whip-poor-will responded negatively to roads on a landscape scale. The effect of road mortality on both species decline has not yet been quantified, nor have 
relative night/day traffic on the logging roads. Therefore, the potential for road mortality to contribute to these species rapid declines also needs further study in this region.

\section{Responses to open wetland amount}

The positive responses of both species to open wetland amount are particularly striking given that I actually attempted to limit variation among sites in open wetland. This was to control for it as a potentially confounding variable. The positive response to wetland amount is a novel finding, largely because the landscape-scale habitat effects on these bird species have not been well studied. Two other studies found a weakly positive effect of wetland area (English et al. 2017) and amount of open area including wetlands (Purves 2015) respectively, on Eastern Whippoor-will at a landscape-scale: though these studies were not in the boreal forest.

These findings are in conflict with some older literature that suggest that wetland are sub-optimal foraging and nesting habitat for Eastern Whip-poor-will (Batzer and Wissinger 1996; Cink 2002). This may be because wetlands in more southern areas are connoted as aquatic-like systems. However, my previous work, (Farrell et al 2017) found that both species were equally associated with wetlands compared to burned stands and clearcuts in the boreal forest. This could be because wetlands in this area can be terrestrial-like or ephemerally wet areas that could host nesting sites on their edges, and high abundance of terrestrial or aquatic-breeding insects (Appendix VIII). Regardless of whether the species are directly nesting on wetlands, it is evident from these findings that wetlands are important habitat to them both on the local and landscape scale. It is possible that in other parts of the species range, where other anthropogenic activity like agriculture and urban development occurs, both Common Nighthawk and Eastern Whippoor-will may be similarly supplementing/meeting their foraging requirements by using wetlands 
in the landsacpes surrounding their nests. However, to test this theory, one would have to control for the amount of other landcover types, similar to what I have done here by isolating (burned stands) or limiting the amount of (wetlands) certain cover types in order to discern a true effect.

I suggest that open wetlands are of particular importance to Common Nighthawk and Eastern Whip-poor-will in the boreal forest because of its value as habitat for insect prey. Open wetlands, unlike clearcuts, do not undergo herbicide application and are known to host high insect diversity and abundances (Spitzer and Danks 2006; Chaundry-Smart et al. 2012) including important prey species of Common Nighthawk and Eastern Whip-poor-will (Todd et al. 1998; Cobb et al. 2006; Iglay et al. 2012; Stark et al. 2012). An alternative explanation for the positive response of Eastern Whip-poor-will to open wetlands is that it is a statistical artefact. My study sites were clustered into two regions, the more western Boreal Hardwood Transition region and the more eastern Boreal Softwood Shield region. The western landscapes, where Eastern Whip-poor-will occupancy was higher (Fig. 3.1), also had a higher proportion of open wetlands (see Appendix VII). Therefore, the positive responses of the Eastern Whip-poor-will to open wetland amount might in fact be a response to region. However, I think this is unlikely as Common Nighthawk, a species known to select similar habitat, did not show higher occupancy in the western region, yet still responded positively to open wetlands. In addition, this explanation seems unlikely because in contrast to my clearcut variables which showed little influence on occupancy: open wetland consistently had positive effects at multiple scales for both species (Fig. 2.3, Fig. 3.2, Appendix III) (Farrell et al. 2017). Thus, it is likely that landscapes with higher amounts of open wetland do indeed support a higher occupancy of both species (Fig. 4.1).

Scale of effect of open wetland 
I found that Common Nighthawk responds to open wetlands at a smaller spatial scale (1.5 km) than Eastern Whip-poor-will $(5.0 \mathrm{~km})$. I suggest this difference is due to foraging behaviours. Though previously I supported the independence of my site by the generally accepted foraging distances/home range sizes of these species, both species are known to forage away from their nest sites to meet their insect food requirement (Aldridge and Brigham 1991; Roth and Jones 2000; Rand 2014), often further than the generally accepted distances/ranges (Rand 2014). Thus, though this may mean that some of my landscapes "overlap" and thus the spatial independence of some sites is not ideal, I can state that these estimated scales of effect may demonstrate rough foraging sizes for these species.

I can postulate, given I found Common Nighthawk and Eastern Whip-poor-will respond positively to open wetlands, not clearcuts at larger scales, that open wetland is their primary foraging habitat in these landscapes. Common Nighthawk, unlike Eastern Whip-poor-will, defend their foraging territories, sometimes aggressively, using their "boom" call (Roth and Jones 2000; Environment Canada 2016). They also forage in flight which may explain why they select landscapes with higher amounts of wetlands surrounding their defended territories. Therefore, Common Nighthawk may be able to travel less far to find food. Eastern Whip-poorwill however, do not typically forage in flight, and instead perch and fly smaller distances to catch prey (Cink 2002). However, Eastern Whip-poor-will are also known to fly large distances to forage if local conditions - like those in a clearcut - are limiting food availability (Rand 2014). Eastern Whip-poor-will may respond to wetlands on a larger scale because of a need to travel further to find food, and to avoid territorial aggression of foraging Common Nighthawk like those empirically demonstrated with other nightjars by Bjorklund and Bjorklund (1983).

\section{Local covariates}


The covariate with the highest explanatory power for Common Nighthawk was the forest type of the clearcut edge (coniferous, mixedwood coniferous, or deciduous). I suggest this is because of the association of coniferous trees to rocky substrates (Whitesides and Bekker 2011). Common Nighthawk occupancy was significantly higher in clearcuts abutted by coniferous mature forest compared to other types. Common Nighthawk are considered habitat generalists and are able to nest in a variety of sites, including agricultural fields, areas, dunes, beaches, burned stands, grasslands, and forest edges (Canterbury et al. 2002; Brigham et al. 2011; Environment Canada 2016). Lohnes (2010) found $96 \%$ of Common Nighthawk nests occurred on bare ground and rock. Coniferous trees in this study area are able to thrive, more than deciduous trees, in rocky substrate because of their shallow root systems (Whitesides and Bekker 2011). Coniferous stands are therefore more likely to have suitable nesting habitat than mixedwood or hardwood stands. It is more likely Common Nighthawk's strong relationship to coniferous stands is a similar association to rocky nesting sites as observed by Lohnes (2010) and others (Cink 2002; Barton 2007).

Species occupancy levels

I found the mean probability of occupancy of Common Nighthawk and Eastern Whip-poor-will to be 0.674 and 0.273 respectively. My estimate for Common Nighthawk is higher than that for a previous study (0.426, Stenger et al. 2011). However, the estimate for Eastern Whip-poor-will is lower than what I found previously in a study of occupancy probability among clearcuts, open wetlands and burned stands where the mean across the three habitats was 0.413 (Farrell et al. 2017). My estimate in this study is also lower than other studies in more southern landscapes in eastern Ontario (0.760 Tozer et al. 2014) and in the southern U.S.A. (0.748, Twedt 2015). Though the fact that I studied Eastern Whip-poor-will at the northern part of its range may 
explain why I observed lower occupancy estimates than other studies at more southern latitudes, it does not explain why my occupancy estimate for Eastern Whip-poor-will are lower than my recent work in this study area (Farrell et al. 2017). Instead, I suggest that the lower occupancy values for Eastern Whip-poor-will in this study compared to my earlier study could be because the species may be less likely to use clearcuts compared to burned stands (Farrell et al. 2017, Appendix VI) or because of road mortality. Another possible explanation for lower occupancy estimates could be due to events/processes in Eastern Whip-poor-will wintering grounds, as little is known about the threats associated with that stage of their life cycle (Environment Canada 2015). For example, year-to-year fluctuations in occupancy probability on the breeding grounds might be related to annual fluctuations in the quality of winter habitat during the previous nonbreeding season (Wilson et al. 2011; Rushing et al. 2017).

\section{Detectability: implications for sampling}

I found strong effects of the time of sampling on detections of both species. These effects suggest ways that future studies can improve detectability of these species. In particular, when sampling for Common Nighthawk, researchers should be sure to sample well after sunset and near sunrise and when sampling for Eastern Whip-poor-will researchers should be sure to sample before and at sunrise and to avoid sampling during rain.

\section{Conclusions}

In conclusion, and in contrast to my expectations, Common Nighthawk and Eastern Whip-poorwill occupancy were not significantly higher in landscapes with a higher proportion of clearcut, irrespective of the age of clearcut analyzed. Given that these species do select clearcut edges as 
breeding sites, it seems possible that clearcuts are acting as ecological traps as they may appear similar to open wetlands but are actually lower quality habitats. This idea is supported by my findings that both species, especially Eastern Whip-poor-will, showed positive responses to the proportion of open wetland in the surrounding landscape. Eastern Whip-poor-will may have selected landscapes that contained higher proportions of open wetlands not just for foraging potential as stated earlier, but also for nesting habitat. This emphasizes the importance of wetlands for the persistence of these species at risk in the boreal forest.

Future studies should expand on these findings at a landscape scale. In particular we need to understand if clearcuts are acting as ecological traps compared to open wetlands. This could be addressed with a study design that varies in the type of open habitat at the local scale while controlling for the proportion of each type of open habitat at the landscape scale. For example, one could estimate occupancy probability in 1) clearcut edges with a surrounding landscape that is predominantly clearcut, 2) clearcut edges with a surrounding landscape that is predominantly wetland, 3) wetland edges with a surrounding landscape that is predominantly clearcut and 4) wetland edges with a surrounding landscape that is predominantly wetland. Future research at the local scale could also address adult survival and reproductive success of Common Nighthawk and Eastern Whip-poor-will nesting in clearcuts versus other open habitats. These studies should examine these effects at multiple spatial scales to inform management decisions and recovery strategies for species at risk that act on larger scales. 
Table 2.1. AICc table showing top models of total clearcut and age-specific occupancy model analysis for Common Nighthawk and Eastern Whip-poor-will at boreal forest sites in northwestern Ontario. Top detection variables for Common Nighthawk (time) and Eastern Whip-poor-will (time+rain) were included in models but are not shown. $\triangle \mathrm{AICc}=$ change in Akaike's Information Criteria corrected for small sample size, wi = Akaike weights, $\mathrm{K}=$ number of model parameters.

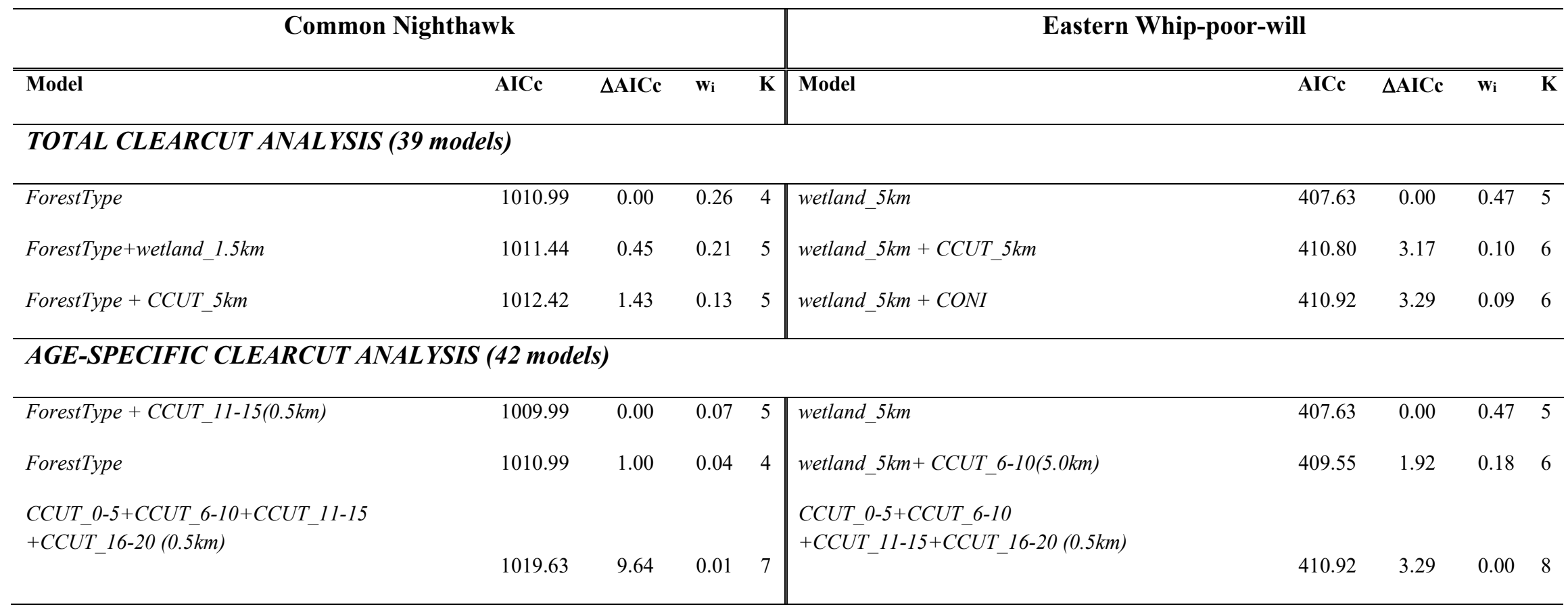

ForestType $=$ dominant tree type of old growth forest at edge of clearcut (i.e. coniferous $/$ deciduous $/$ mixed), wetland_ $X \mathrm{~km}=$ proportion of wetland area within a given km radius, $C C U T \_5 \mathrm{~km}=$ proportion of total clearcut area (0-15 years old), CCUT_0-5/6-10/11-15/16$20(\mathrm{Xm})=$ proportion of clearcut area of a given age class $(0-5,6-10,11-15,16-20$ years old) within given radius $(\mathrm{Xkm})$. 
Table 3.1. Correlations among predictor spatial variables found among the best models (Table $\mathrm{X})$ measured with Spearman rank correlation values. The highest correlated variables are the proportion of wetland at $5 \mathrm{~km}$ and at $1.5 \mathrm{~km}$ and the proportion of total clearcut area and clearcuts 6-10 years old at $5 \mathrm{~km}$.

\begin{tabular}{|c|c|c|c|c|c|}
\hline & wetland_1.5km & wetland_5km & CCUT_5km & CCUT_11-15 $(0.5 \mathrm{~km})$ & CCUT_6-10 (5km) \\
\hline wetland_1.5km & - & - & - & - & - \\
\hline wetland_5 $\mathrm{km}$ & 0.90 & - & - & - & - \\
\hline CCUT_5km & 0.48 & 0.54 & - & 一 & 一 \\
\hline $\begin{array}{l}\text { CCUT_11-15 } \\
(0.5 \mathrm{~km})\end{array}$ & -0.42 & -0.37 & -0.12 & 一 & 一 \\
\hline $\begin{array}{l}\text { CCUT_6-10 } \\
(5 \mathrm{~km})\end{array}$ & 0.46 & 0.54 & 0.66 & -0.28 & - \\
\hline
\end{tabular}




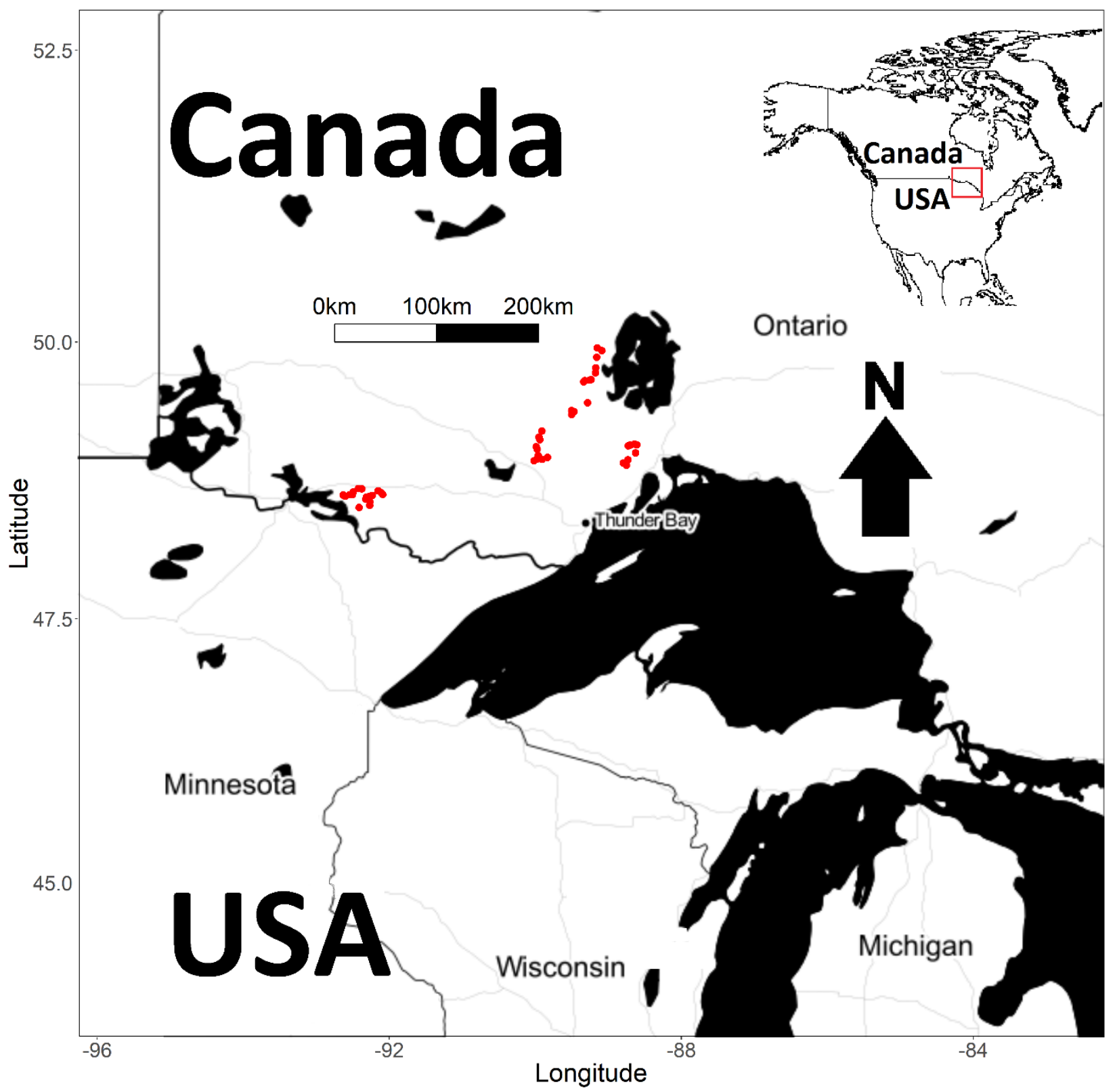

Fig. 2.1. Distribution of sampling sites for Common Nighthawk and Whip-poor-will across northwestern Ontario, northwest of Thunder Bay, Ontario, Canada. Each red dot represents one sampling site on a recent clearcut edge. General location of the study area in North America is represented as the red square in the inset image of North America (top right). 


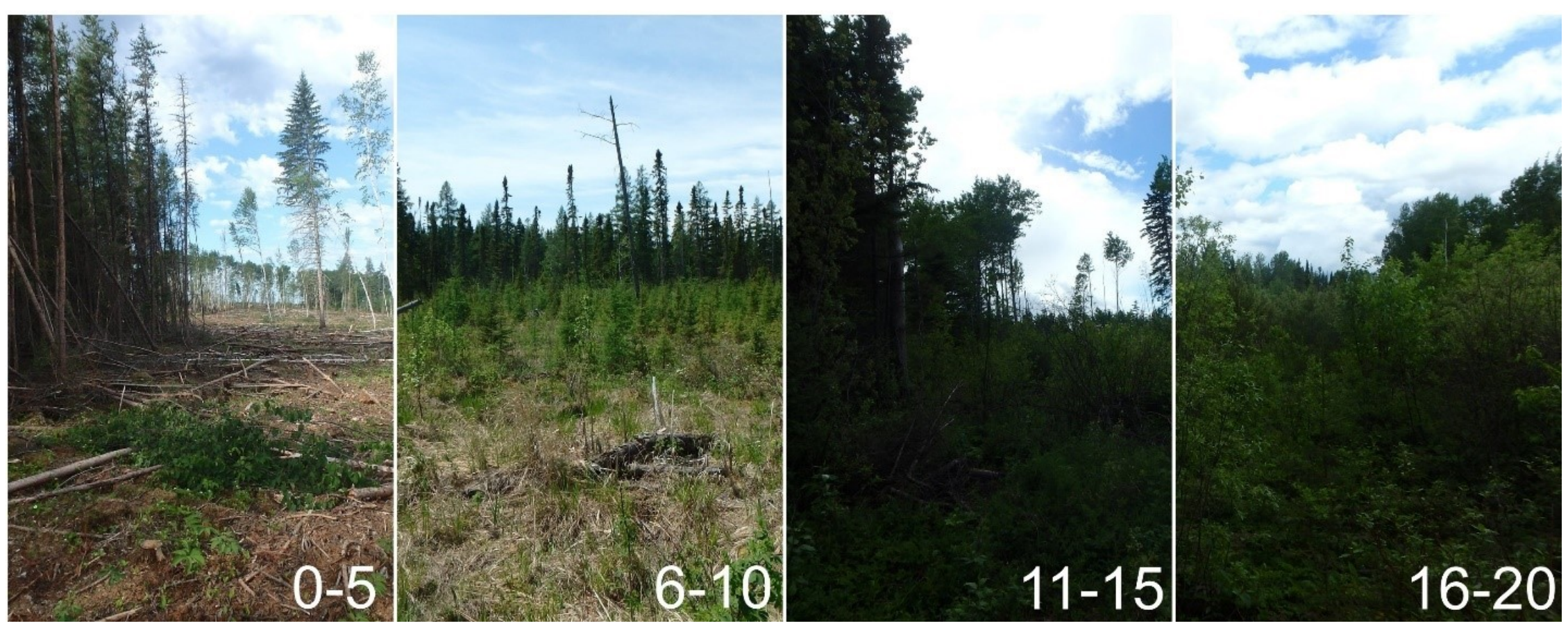

Fig. 2.2. Age-based variation in clearcut patches found in Common Nighthawk and Eastern Whip-poor-will range in northwestern Ontario. Captions on the bottom right represent different ages of clearcuts and the regrowth associated with that age range (0-5, 6-10, 11-15, and 16-20 years old). The first three age ranges represent fairly open habitat whereas the older clearcuts in the 16-20 year old range demonstrate how regrowth can reduce open habitat. 


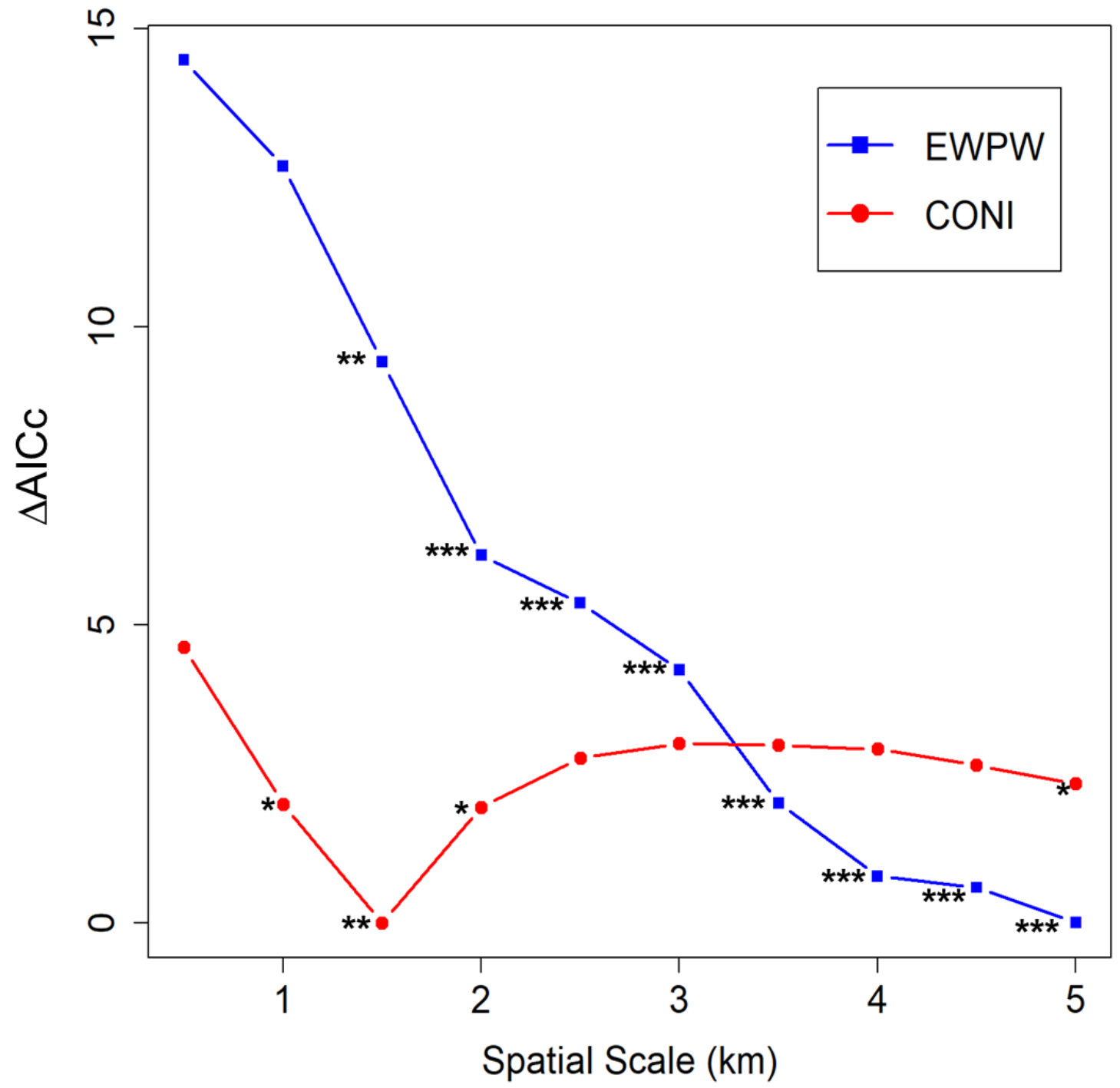

Fig. 2.3. Relationship between species occupancy of Eastern Whip-poor-will (EWPW) and Common Nighthawk (CONI) and the proportion of open wetland at different spatial scales evaluated using the change in Akaike's Information Criteria corrected for small sample size $(\triangle \mathrm{AICc})$. The lowest points in these curves represent the scale of effect where the relationship is strongest/variation in the response is best explained by the predictor. Significance is indicated with an $* *(\mathrm{p}<0.05)$ or $* * *(\mathrm{p}<0.01)$ at that spatial scale with $*$ indicating $\mathrm{p}<0.1$ but $>0.05$. 


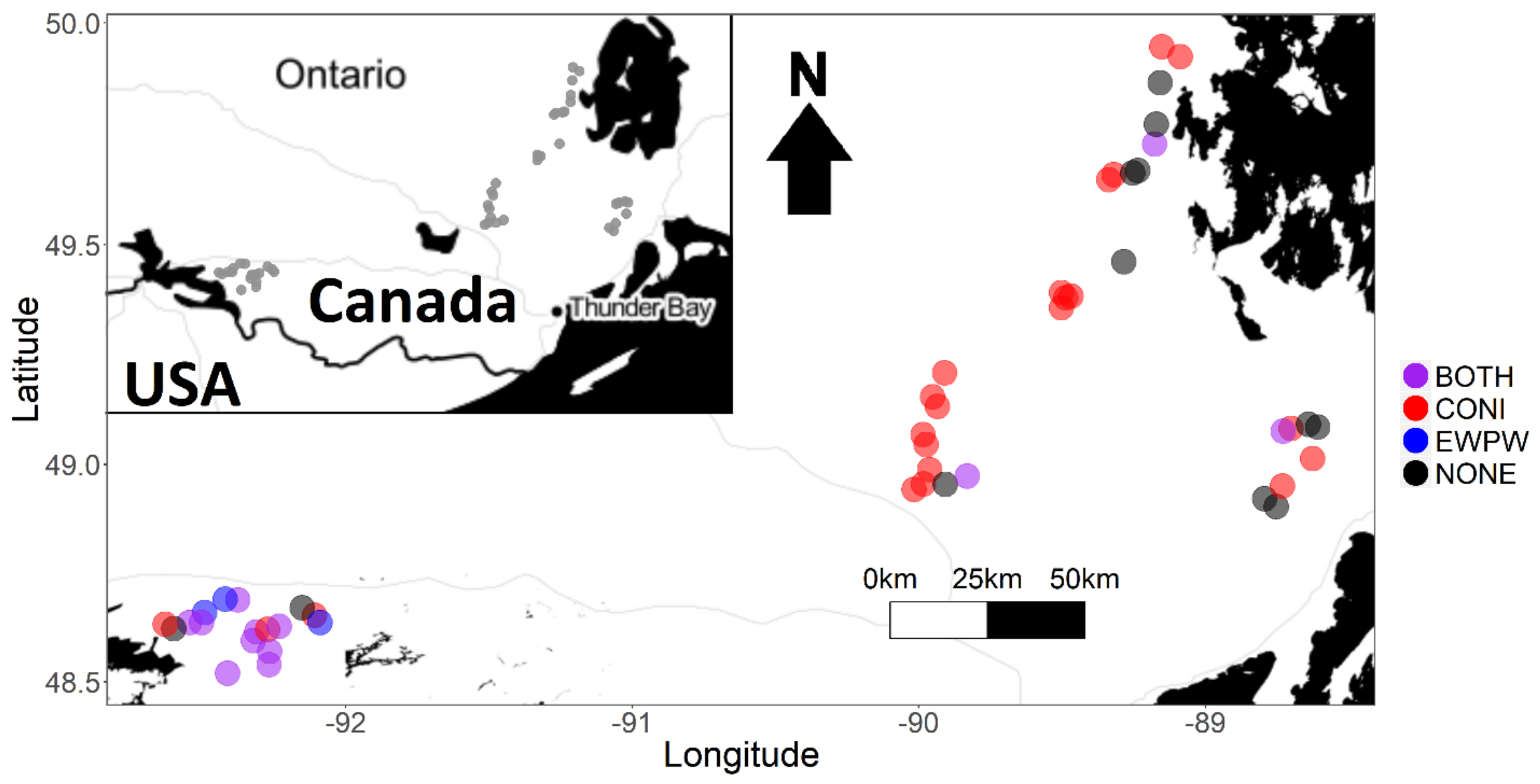

Fig. 3.1. Sampling sites showing detection of Common Nighthawk (CONI) and Eastern Whip-poor-will (EWPW). Purple circles represent sampling sites with detection of both CONI and EWPW, blue circles represent sampling sites where only CONI were detected, red circles represent sampling sites where only EWPW were detected, and black circles represent sampling sites where neither CONI nor EWPW were detected. The inset image in the top left shows the distribution of sites in the study area northwest of Thunder Bay, Ontario, Canada. 


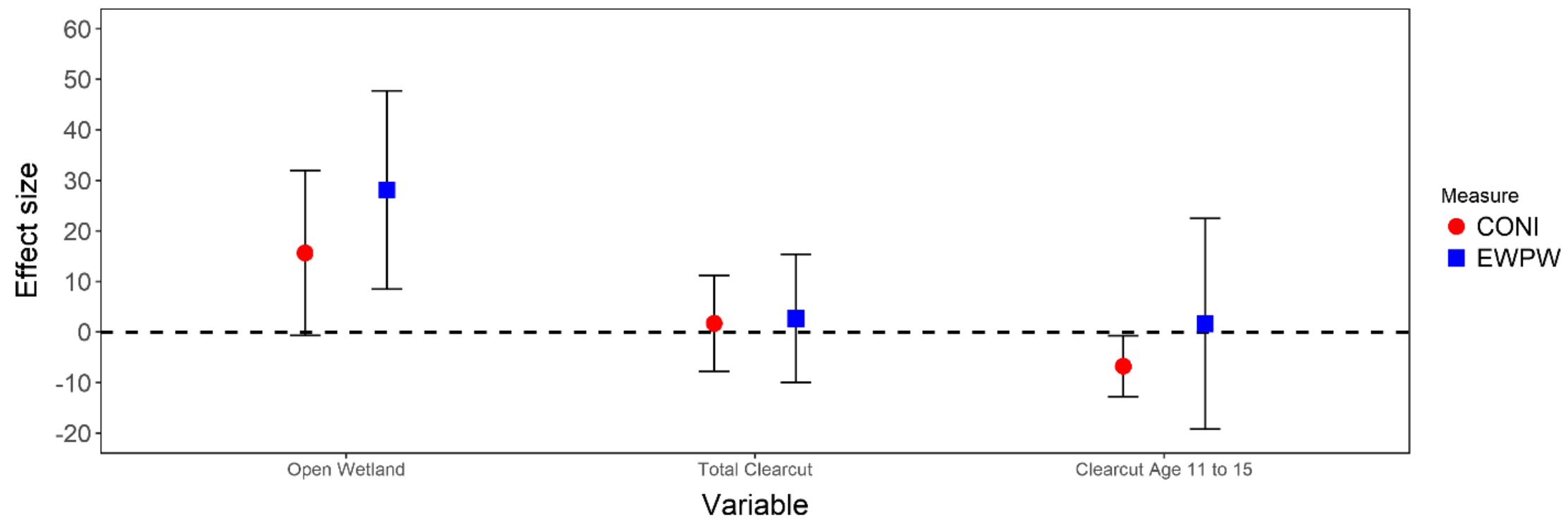

Fig. 3.2. Model coefficient effect sizes for the influence of the proportion of open wetland at the scale of effect, the proportion of total recent $(\leq 15$ years old) clearcut and the proportion of clearcut (11-15 years old) at their scales of effect. Coefficient values were taken from best model sets of both species (see Table 1). To demonstrate effects of all variables we report the coefficient value and $95 \%$ confidence intervals. 


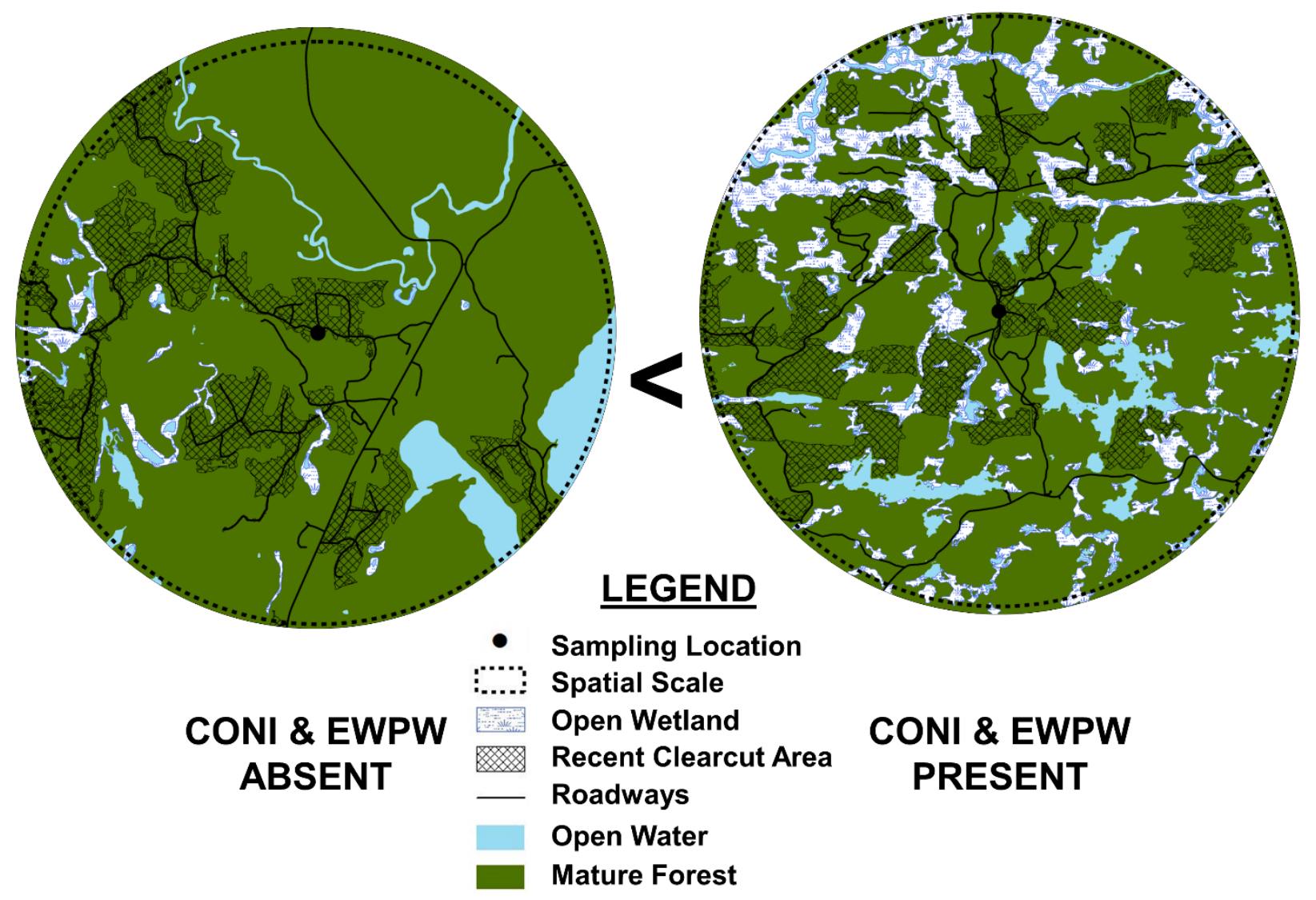

Fig. 4.1. Two sample landscapes ( $5.0 \mathrm{~km}$ radius). The left image shows a landscape with recent clearcut area where both Common Nighthawk (CONI) and/or Eastern Whip-poor-will (EWPW) were not detected. The right image shows a landscape also with recent clearcut area, but with a much higher proportion of open wetland area, where both Common Nighthawk (CONI) and Eastern Whip-poor-will were detected. This comparison represents one of the main conclusions of the study; both Common Nighthawk and Eastern Whip-poor-will respond more strongly (positively) to open wetland area on a landscape-scale than to recent clearcut area. Thus, according to my findings, a landscape with a greater proportion of open wetland (right) has a higher probability of occupancy for Common Nighthawk and Eastern Whip-poor-will. Produced by (Claire E. Farrell) under Licence with the Ontario Ministry of Natural Resources and Forestry@ Queen's Printer for Ontario, 2017 


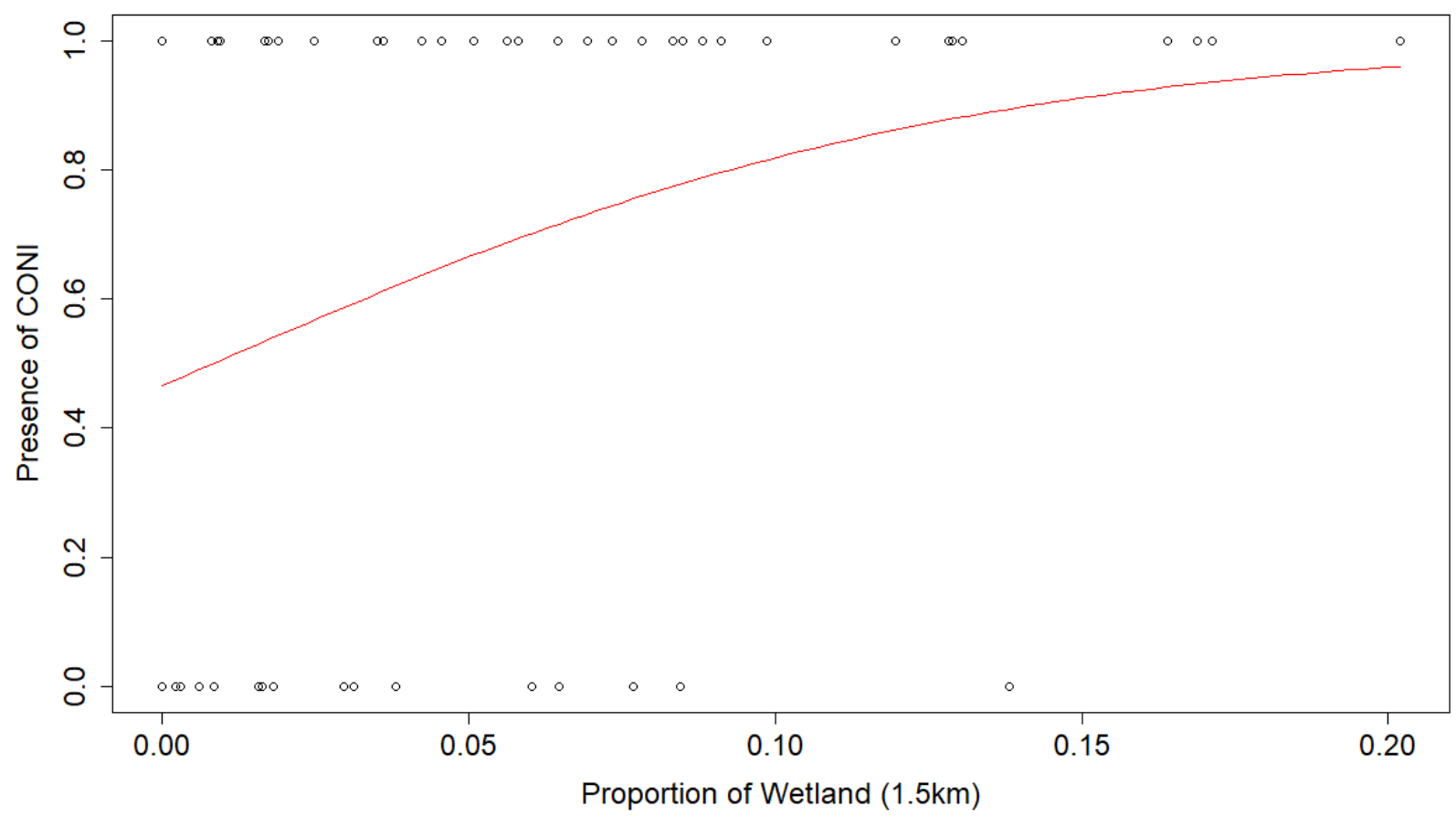

Fig. 4.2. Presence (1) and absence (0) of Common Nighthawk (CONI) in northwestern Ontario, Canada, May-July 2017, as a function of proportion of open wetland within a radius of $1.5 \mathrm{~km}$ (the scale-of-effect). Shown are circles each representing one of 49 sampling sites, and a line of best fit. 


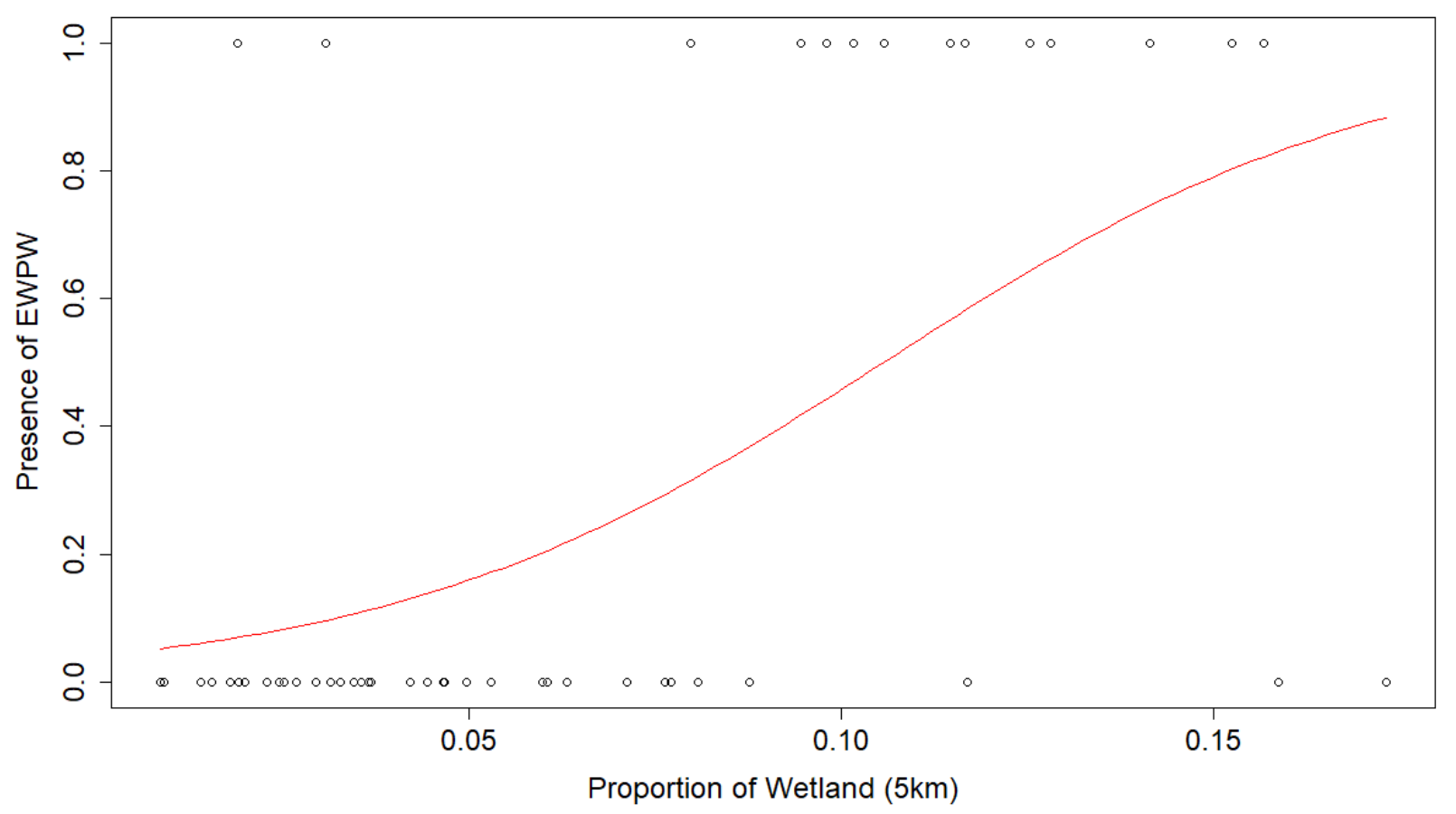

Fig. 4.3. Presence (1) and absence (0) of Eastern Whip-poor-will (EWPW) in northwestern Ontario, Canada, May-July 2017, as a function of proportion of open wetland within a radius of $5.0 \mathrm{~km}$ (the scale-of-effect). Shown are circles each representing one of 49 sampling sites, and a line of best fit. 


\section{Literature Cited}

Akresh, M.E., King, D.I., 2016. Eastern Whip-poor-will breeding ecology in relation to habitat management in a pitch pine-scrub oak barren. Wildlife Soc. B.

http://dx.doi.org/10.1002/wsb.621.

Aldridge HDJN, Brigham RM. (1991) Factors influencing foraging time in two aerial insectivores: the bird Chordeiles minor and the bat Eptesicus fuscus. Can. J. Zool. 39: 62-69.

Alexander I, Cresswell B. (1990) Foraging by nightjars caprimulgus-europaeus away from their nesting areas. IBIS 132: 568-574.

Allen TFH, Hoekstra TW. (1990) The confusion between scale-defined levels and conventional levels of organization in ecology. J. Veg. Sci. 1: 5-12.

Armstrong JT. (1965) Breeding home range in the nighthawk and other birds; its evolution and ecological significance. Ecology 46:619-629.

Barton BJ. (2007) Whip-poor-will and Common Nighthawk Surveys in Support of the Michigan Breeding Bird Atlas II - 2007 Final Report. Report Number MNFI 2007-17. Report to the Michigan Department of Natural Resources, Wildlife Division, Lansing, MI. 323 pp +. appendices.

Barton K. (2018) MuMIn: multi-model inference. < https://cran.rproject.org/web/packages/MuMIn/MuMIn.pdf> Accessed 15 August 2018.

Batzer DP, Wissinger SA. (1996) Ecology of insect communities in nontidal wetlands. Annual Review of Entomology 41:75-100.

Bayne E, Hobson K. (2000) Relative use of contiguous and fragmented boreal forest by red squirrels (Tamiasciurus hudsonicus). Can. J. Zoo. 78: 359-365.

Becker FS, Wood PB, Keyser PD, Wigley TB, Dellinger R, Weakland CA. (2011) Threshold responses of songbirds to long-term timber management on an active industrial forest. For. Ecol. Manag. 262: 449-460.

Bender DJ, Brigham RM. (1995) Preliminary inventory manual for sampling goatsuckers (Caprimulgidae) in British Columbia, Resource Inventory Committee. Ministry of Environment, Wildlife Branch.

Bishop CA, Brogan JM. (2013) Estimates of avian mortality attributed to vehicle collisions in Canada. Avian Conservation and Ecology 8: 2.

Bjorklund R, Bjorklund E. (1983) Notes on the behavior and nesting of caprimulgids in the Sand Ridge State Forest. III. Aud. Bull. 84: 492-493. 
Bock EF, Lynch JF. (1970) Breeding bird populations of burned and unburned conifer forest in the Sierra Nevada. The Condor 72: 182-189.

Brennan J, Bender DJ, Conteras TA, Fahrig L. (2002) Focal patch landscape studies for wildlife management: Optimizing sampling effort across scales. Pages 68-91 in Liu J Taylor WW, eds. Integrating Landscape Ecology into Natural Resource Management . Cambridge (United Kingdom): Cambridge University Press.

Brigham RM, Fenton MB. (1991) Convergence in foraging strategies by two morphologically and phylogenetically distinct aerial insectivores. J. Zool. 223: 475-489.

Brigham, R.M., Ng, J., Poulin, R.G., Grindal, S.D., 2011. Common nighthawk (Chordeiles minor). In: Poole, A. (Ed.), The Birds of North America Online. Cornell Lab of Ornithology, Ithica, NY.

Burnham KP, Anderson DR. (2002) Model Selection and Multi-Model Inference: A Practical Information-Theoretic Approach. Springer, New York, New York, USA.

Canterbury GE, Martin TE, Petit DR, Petit LJ, Bradford DF. (2000) Bird communities and habitat as ecological indicators of forest condition in regional monitoring. Conserv. Biol. 14: 544-558.

Chaundry-Smart RFC, Smith SM, Malcolm JR, Bellocq MI. (2012) Comparison of moth communities following clear-cutting and wildfire disturbance in the southern boreal forest. For. Ecol. Manag. 270: 273-281.

Chubbs TE, Keith LB, Mahoney SP, McGrath MJ. (1993) Responses of woodland caribou (Rangifer tarandus caribou) to clear-cutting in east-central Newfoundland. Canadian Journal of Zoology 71: 487-493.

Cink CL. (2002) Eastern Whip-poor-will (Antrostomus vociferous). In: Poole, A. (Ed.), The Birds of North America Online. Cornell Lab of Ornithology, Ithica, NY.

Cobb, TP, Langor DW, Spence JR. (2007) Biodiversity and multiple disturbances: boreal forest ground beetle (Coleoptera:Carabidae) responses to wildfire, harvesting and herbicide. Canadian Journal of Forest Research 37: 1310-1323.

Committee on the Status of Endangered Wildlife in Canada (COSEWIC). (2007) COSEWIC assessment and status report on the Common Nighthawk Chordeiles Minor in Canada.

Committee on the Status of Endangered Wildlife in Canada, Ottawa, ON

$<$ http://www.sararegistry.gc.ca/virtual_sara/files/cosewic/sr_chordeiles_minor_e.pdf $>$

Committee on the Status of Endangered Wildlife in Canada (COSEWIC). (2009) COSEWIC Assessment and Status Report on the Eastern Whip-Poor-Will Caprimulgus Vociferus in Canada. 
Committee on the Status of Endangered Wildlife in Canada, Ottawa, ON

$<$ http://www.sararegistry.gc.ca/virtual_sara/files/cosewic/sr_whip-poor-will_0809_e.pdf>.

Davis PR. (1977) Cervid response to forest fire and clearcutting in southeastern Wyoming, The Journal of Wildlife Management 41: 785-788.

DeGraaf RM, Yamasaki M. (2003) Options for managing early-successional forest and shrubland bird habitats in the northeastern United States. For. Ecol. Manag. 185: 179-191.

Degregorio BA, Chiavacci SJ, Benson TJ, Sperry JH, Weatherhead PJ. (2016) Nest predators of North American birds: continental patterns and implications. BioScience 66: 655-665.

Delong SC, Tanner D. (1996) Managing the pattern of forest harvest: lessons from wildfire. Biodiver. Conserv. 5: 1191-1205.

Downes CM, Collins BT, Damus M. (2005) Canadian Bird Trends Web site Version 2.1. Migratory Birds Conservation Division, Canadian Wildlife Service, Gatineau, Quebec.

Duguay JP, Wood PB, Miller GW. (2000) Effects of timber harvests on invertebrate biomass and avian nest success. Wildlife Society Bulletin 28: 1123-1131.

English PA, Nocera JJ, Pond BA, Green DJ. (2017) Habitat and food supply across multiple spatial scales influence the distribution and abundance of a nocturnal aerial insectivore.

Landscape Ecology 32: 343-359.

Environment Canada. (2012) Recovery Strategy for the Woodland Caribou (Rangifer tarandus caribou), Boreal population, in Canada. Species at Risk Act Recovery Strategy Series.

Environment Canada, Ottawa. xi +138 pp.

Environment Canada. (2014a) Bird Conservation Strategy for Bird Conservation Region 12 in Ontario and Manitoba: Boreal Hardwood Transition. Canadian Wildlife Service, Environment Canada, Ottawa, ON

$<$ http://www.nabci.net/Canada/English/pdf/BCR\%2012\%20ON\%20FINAL_June2014.pdf>.

Environment Canada. (2014b) Bird Conservation Strategy for Bird Conservation Region 8 in Ontario Region: Boreal Softwood Shield. Canadian Wildlife Service, Environment Canada, Ottawa, ON

$<$ http://www.nabci.net/Canada/English/pdf/BCR\%208\%20ON\%20FINAL_11September2014.pd f>.

Environment Canada. (2014c) North American Breeding Bird Survey - Canadian Results and Analysis Website version 3.00. Environment Canada, Gatineau, Quebec. Accessed 15 June 2014.

Environment Canada. (2014d) North American Breeding Bird Survey - Canadian Trends Website, Data-version 2012. Environment Canada, Gatineau, Quebec, K1A 0H3. 
Environment Canada. (2015) Recovery strategy for eastern whip-poor-will (Antrostomus vociferous) in Canada. Species at Risk Act Recovery Strategy Series. Environment Canada, Ottawa. vii $+57 \mathrm{pp}$.

Environment Canada. (2016) Recovery strategy for common nighthawk (Chordeiles minor) in Canada. Species at Risk Act Recovery Strategy Series. Environment Canada, Ottawa. vii +49pp.

Farrell CE, Wilson S, Mitchell G. (2017) Assessing the relative use of clearcuts, burned stands, and wetlands as breeding habitat for two declining aerial insectivores in the boreal forest. For. Ecol. Manag. 386: 62-70.

Fisher JT, Wilkinson L. (2005) The response of mammals to forest fire and timber harvest in the North American boreal forest. Mammal Review 35: 51-81.

Fiske I, Chandler R. (2014) Overview of Unmarked: An R Package for the Analysis of Data from Unmarked Animals.

Garlapow RM. (2007) Whip-poor-will prey availability and foraging habitat: implications for management in a pitch pine/scrub oak barren habitats. Masters Thesis. University of Massachussets.

Hagar J, Howlin S, Ganio L. (2004) Short-term response of songbirds to experimental thinning of young Douglas-fir forests in the Oregon Cascades. For. Ecol. Manag. 199: 333-347.

Haila Y, Hanski IK, Niemelä J, Punttila P, Raivio S, Tukia H. (1994) Forestry and the boreal fauna: matching management with natural forest dynamics. Ann. Zool. Fenn. 31: 187-202.

Hins C, Ouellet J, Dussault C, St-Laurent M. (2009) Habitat selection by forest-dwelling caribou in managed boreal forest of eastern Canada: Evidence of a landscape configuration effect. For. Ecol. Manag. 31: 636-643.

Hobson K., Bayne E. (2000) Breeding bird communities in boreal forest of western Canada: consequences of "unmixing" the mixedwoods. The Condor 102: 759-769. doi:10.2307/1370303

Hoffman, T. (2018) MoonCalc.

https://www.mooncalc.org/\#/48.9225,90.5057,3/2018.06.19/11:28/1/0. Accessed 19 June 2018.

Hollander FA., Van Dyck H, Martin GS, Titeux N. (2011) Maladaptive habitat selection of a migratory passerine bird in a human-modified landscape. PLOS One 6: e25703.

Hunter Jr ML. (1990) Wildlife, Forests and Forestry: Principles of Managing Forests for Biological Diversity. Prentice-Hall, Englewood Cliffs, NJ.

Hunter Jr ML. (1993) Natural fire regimes as spatial models for managing boreal forests. Biolog. Conser. 65: 115-120. 
Hurvich CM, Tsai CL (1989) Regression and time series model selection in small samples. Biometrika 76: 297-307.

Hutto RL, Hejl SJ, Preston CR, Finch D. (1993) Effects of silvicultural treatments on forest birds in the Rocky Mountains: implications and management recommendations. In Status and management of Neotropical migratory birds. Edited by D.M. Finch and P.W. Stangel. U.S. Dep. Agric. For. Ser. Gen. Tech. Rep. RM-229. pp. 386-391.

Iglay, RB, Miller DA, Leopold BD, Wang G. (2012) Carabid beetle response to prescribed fire and herbicide in intensively managed, mid-rotation pine stands in Mississippi. Forest Ecology and Management 281: 41-47.

Jack J, Rytwinski T, Fahrig L, Francis CM. (2015) Influence of traffic mortality on forest bird abundance. Biodiversity and Conservation 24: 1507-1529.

Jackson HD. (2003) A field survey to investigate why nightjars frequent roads at night. Ostrich 74: $97-101$.

Jackson HB, Fahrig L. (2015) Are ecologists conducting research at the right scale? Global Ecology and Biogeography 24: 52-63.

Janssen P, Fortin D, Christian H. (2009) Beetle diversity in a matrix of old-growth boreal forest: influence of habitat heterogeneity at multiple scales. Ecography 32: 423-432.

Kellner KF, Ruhl PJ, Dunning JB, Riegel JK, Swihart RK. (2016) Multi-scale responses of breeding birds to experimental forest management in Indiana, USA. For. Ecol. Manag. 382: 6475 .

Kirk DA, Diamond AW, Hobson KA, Smith AR. (1996) Breeding bird communities of the western and northern Canadian boreal forest: relationship to forest type. Can. J. Zool. 74: 17491770 .

Kirk DA, Hobson KA. (2001) Bird-habitat relationship in jack pine boreal forests. For. Ecol. Manag. 147: 217-243.

Knight EC, Ng JW, Mader CE, Brigham RM, Bayne EM. (2018) An inordinate fondness for beetles: first description of common nighthawk (Chordeiles minor) diet in the boreal biome. The Wilson Journal of Ornithology 130: 525-531.

Kotliar NB, Heijl SJ, Hutto VA, Saab CP, Melcher C, McFadzen ME. (2002) Effects of fire and postfire salvage logging on avian communities in conifer dominated forests of the western United States. Studies in Avian Biology 25:49-64.

Legrand HG, Chamberlain MJ, Moser EB. (2007) Diversity and abundance of breeding birds in a managed loblolly pine forest in Louisiana. The American Midland Naturalist 157: 329-344. 
Lehnen SE, Rodewald AD. (2009) Investigating area-sensitivity in shrubland birds: Responses to patch size in a forested landscape. For. Ecol. Manag. 257: 2308-2316.

Lohnes RG. (2010) Nest site selection and nest thermal properties of common nighthawks on the tallgrass prairie of Kansas. Cornell University. Ithaca, New York. viii + 23pp.

Lorimer CG, White AS. (2003) Scale and frequency of natural disturbances in the northeastern US: implications for early successional forest habitats and regional age distributions. For. Ecol. Manag. 185: 41-64.

Mackenzie DI, Nichols JD, Lachman GB, Droege S, Royle JA, Langtimm CA. (2002) Estimating site occupancy rates when detection probabilities are less than one. Ecology 83:

McRae DJ, Duchesne LC, Freedman B, Lynham TJ, Woodley S. (2001) Comparisons between wildfire and forest harvesting and their implications in forest management. Environ. Rev. 9: 223-260.

Mills AM. (1986) The influence of moonlight on the behavior of goatsuckers (Caprimulgidae). The Auk 2: 370-378.

Moorman CE, Russell KR, Greenberg CH. (2011) Reptile and amphibian response to hardwood forest management and early successional habitats. Sustaining Young Forest Communities in Managing Forest Ecosystems Series 21: 191-208.

Morrison ML, Meslow EC. (1983) Avifauna associated with early growth vegetation on clearcuts in the Oregon coast ranges. United States Department of Agriculture, Pacific Northwest Forest and Range Experiment Station. $<$ https://www.fs.fed.us/pnw/pubs/pnw_rp305.pdf > Accessed 15 August 2018.

Natural Resources Canada (NRCAN). (2017) 8 facts about Canada's boreal forest. https://www.nrcan.gc.ca/forests/boreal/17394. Accessed 6 July 2018.

Nebel S, Mills A, McCracken JD, Taylor PD. (2010) Declines of aerial insectivores in North America follow a geographic gradient. Avian Conservation and Ecology - Écologie et conservation des oiseaux 5: 1 .

Nielsen SE, Boyce MS, Stenhouse GB. (2004) Grizzly bears and forestry I:Selection of clearcuts by grizzly bears in west-central Alberta, Canada. For. Ecol. Manag. 199: 51-65.

Ontario Ministry of Natural Resources and Forestry (OMNRF). (2012) Eastern Whip-poor-will. $<$ https://www.ontario.ca/page/eastern-whip-poor-will $>,<$ http://files.ontario.ca/environment-andenergy/species-at-risk/eastern_whip_poor_will_map_eng.pdf $>$.

Ontario Ministry of Natural Resources and Forestry (OMNRF). (2014) Forest Resources Inventory Technical Specifications 2009. Queen's Printer for Ontario. Peterborough, On. 
https://dr6j45jk9xcmk.cloudfront.net/documents/2837/fim-tech-spec-forest-resourcesinventory.pdf. Accessed 19 July 2018.

Ontario Ministry of Natural Resources and Forestry (OMNRF). (2017) Forest Resource Inventory. Queen's Printer for Ontario. Land Information Ontario Database.

https://www.javacoeapp.lrc.gov.on.ca/geonetwork/srv/en/main.home. Accessed 10 January 2018.

Ontario Ministry of Natural Resources and Forestry (OMNRF). (2018a) Management Units and Forest Management Plan Renewal Schedules. https://www.ontario.ca/page/management-unitsand-forest-management-plan-renewal-schedules\#section-0. Accessed 19 June 2018.

Ontario Ministry of Natural Resources and Forestry (OMNRF). (2018b) Ontario's Forest Regions. https://www.ontario.ca/page/forest-regions. Accessed 4 July 2018.

Ontario Ministry of Natural Resources and Forestry (OMNRF). (2018c) Eastern Whip-poor-will. https://www.ontario.ca/page/eastern-whip-poor-will. Accessed 18 July 2018

Poulin RG, Grindal SD, Brigham RM. (1996) Common Nighthawk (Chordeiles minor). The Birds of North America, No. 213 (Poole A, Gill F eds.). The Academy of Natural Sciences, Philadelphia, PA, and the American Ornithologists' Union, Washington, DC.

Purves, E. (2015) The role of breeding habitat loss in the Decline of Eastern Whip-poor-will (Antrostomus vociferous) populations in Canada. Masters Thesis. Queen's University.

Rand, G.J. 2014. Home range use, habitat selection, and stress physiology of Eastern Whip-poorwills (Antrostomus vociferus) at the northern edge of their range. Msc. Thesis, Trent University.

Rietsma LR, Holmes RT, Sherry TW. (1990) Effects of removal of red squirrels, Tamiasciurus hudsonicus, and eastern chipmunks, Tamias striatus, on nest predation in a northern harwood forest: an artificial nest experiment. Oikos 57: 375-380.

Roth A, Jones GS. (2000) Dynamics of territorial behavior by common nighthawks. Northeastern Naturalist 7: 178-180.

Rowe JF, Scotter GW. (1973) Fire in the boreal forest. Quatern. Res. 3: 444-464

Rushing CS, Ryder TB, Marra PP. (2016) Quantifying drivers of population dynamics for a migratory bird throughout the annual cycle. Proceedings of the Royal Society B 283, 2015-2846.

Russell RE, Royle JA, Saab VA, Lehmkuhl JF, Block WM, Sauer JR. (2009) Modeling the effects of environmental disturbance on wildlife communities: avian responses to prescribed fire. Ecological Applications 19:1253-1263. 
Schieck, J, Stuart-Smith K, Norton M. (2000) Bird communities are affected by amount and dispersion of vegetation retained in mixedwood boreal forest harvest areas. For. Ecol. Manag. 126: $239-254$.

Schulte LA, Niemi GJ. (1998) Bird communities of early-successional burned and logged forest. J. Wildl. Manage. 62: 1418-1429.

Shin D, Yoo J. (2016) Reproductive success of Eurasian eagle-owls in wetland and non-wetland habitats of west-central Korea. Journal of Raptor Research 50: 241-253.

Simon NPP, Stratton CB, Forbes GJ, Schwab FE. (2002) Similarity of small mammal abundance in post-fire and clearcut forests. For. Ecol. Manag. 165: 163-172.

Smith, CE. (2012) Initial response of amphibian and small mammal species to timber and coarse woody debris harvest in aspen-dominated forests of northern Minnesota. MSc Thesis. Retrieved from the University of Minnesota Digital Conservancy, http://hdl.handle.net/11299/122207. Accessed 15 July 2018.

Spitzer K, Danks HV. (2006) Insect biodiversity of boreal peat bogs. Annu. Rev. Entomol. 51: 137-161.

Stark JD, Chen XD, Johnson CS. (2012) Effects of herbicides on Behr's metalmark butterfly, a surrogate species for the endangered butterfly, Lange's metalmark. Environmental Pollution 164: 24-27.

Stelfox, JB. 1995. Relationships between stand age, stand structure, and biodiversity in aspen mixedwood forests in Alberta. Alberta Environmental Centre and Canadian Forest Service. Vegreville and Edmonton, AB. pp. 308.

Stenger JM, Rehm-Lorber JA, White CM, Pavlacky Jr DC. (2011) Monitoring the Birds of Agate Fossil Beds National Monument: 2010 Annual Report. Rocky Mountain Bird Observatory, Brighton, Colorado, USA.

Streby HM, Andersen DE. (2013) Movements, cover-type selection, and survival of fledgling ovenbirds in managed deciduous and mixed coniferous-deciduous forests. For. Ecol. Manag. 287: 9-16.

Tews J, Brose U, Grimm V, Tielborger K, Wichmann MC, Schwager M, Jeltsch F. (2004) Journal of Biogeography $31:$ 79-92.

Tews J, Brose U, Grimm V, Tielborger K, Wichmann MC, Schwager M, Jeltsch F. (2004b) Animal species diversity driven by habitat heterogeneity/diversity: the importance of keystone structures. J. Biogeogr. 31: 79-92. 
Thompson DG, Pitt DG. (2011) Frequently Asked Questions (FAQs) On the Use of Herbicides in Canadian Forestty. Canadian Forest Service - Sault Ste. Marie Technical Note No. 112. https://canadiankraftpaper.com/wp-content/uploads/2018/05/CKP-Sustainability-CommunitiesNewsletter-FAQ-Herbicide.pdf. Accessed 12 September 2018.

Todd LD, Poulin RG, Brigham RM. (1998) Diet of common nighthawks (Chordeiles minor: caprimulgidae) relative to prey abundance. The American Midland Naturalist 139: 20-28.

Tozer DC, Hoare JC, Inglish JE, Yaraskavitch J, Kitchin SD. (2014) Clearcut with seed trees in red pine forests associated with increased occupancy by Eastern Whip-poor-wills. For. Ecol. Manag. 330: 1-7.

Twedt DK. (2015) Estimating regional landbird populations from enhanced North American Breeding Bird Surveys. J. Field Ornithol. 86: 352-368.

Tyler, WM. (1940) Eastern Whip-poor-will. U.S. National Museum Bulletin 176: 163-183.

Whitesides CJ, Bekker MF. (2011) Rocky substrate and the lower treeline ecotone of Yellowstone's northern range. Physical Geography 32: 356-373.

Wilson MD, Watts BD. (2006) Effect of moonlight on detection of Whip-poor-wills: implications for long-term monitoring strategies. Journal of Field Ornithology 77: 207-211.

Wilson MD, Watts BD. (2008) Landscape configuration effects on distribution and abundance of Whip-poor-wills. Wilson. J. Ornthol. 120: 778-783.

Wilson S, Ladeau SL, Tøttrup AP, Marra, PP. (2011) Range-wide effects of breeding and nonbreeding season climate on the abundance of a Neotropical migrant songbird. Ecology 92: 17891798.

Wu J. (1999) Hierarchy and scaling: extrapolating information along a scaling ladder. Canadian Journal of Remote Sensing, 25: 367-380.3

Zmihorski M. (2012) The effects of anthropogenic and natural disturbances on breeding birds of managed scots pine forest in northern Poland. Ornis Fennica 89: 63-73. 


\section{APPENDIX I}

\section{Detectability Model Selection and Results}

Table I. AICc table showing ranking of detection models for Common Nighthawk at boreal forest sites in northwestern Ontario. $\triangle \mathrm{AICc}=$ change in Akaike's Information Criteria corrected for small sample size, $w i=$ Akaike weights, $\mathrm{K}=$ number of model parameters.

\begin{tabular}{|c|c|c|c|c|}
\hline Detection & AICc & $\triangle \mathrm{AICc}$ & $\mathbf{w}_{\mathbf{i}}$ & $\mathbf{K}$ \\
\hline time & 1016.62 & 0.00 & 0.26 & 3 \\
\hline time + date & 1017.15 & 0.53 & 0.20 & 4 \\
\hline time+wind & 1018.61 & 1.99 & 0.10 & 4 \\
\hline time + rain & 1019.24 & 2.62 & 0.07 & 4 \\
\hline lunar+time & 1019.35 & 2.73 & 0.07 & 4 \\
\hline time + wind + date & 1019.37 & 2.75 & 0.07 & 5 \\
\hline lunar + time + date & 1019.48 & 2.86 & 0.06 & 5 \\
\hline time + rain + date & 1019.97 & 3.35 & 0.05 & 5 \\
\hline time + rain + wind & 1021.45 & 4.83 & 0.02 & 5 \\
\hline lunar + time + wind & 1021.57 & 4.95 & 0.02 & 5 \\
\hline lunar + time + wind + date & 1022.01 & 5.39 & 0.02 & 6 \\
\hline lunar + time + rain & 1022.10 & 5.48 & 0.02 & 5 \\
\hline time + rain + wind + date & 1022.42 & 5.80 & 0.01 & 6 \\
\hline lunar+time + rain + date & 1022.45 & 5.83 & 0.01 & 6 \\
\hline lunar + time + rain + wind & 1024.57 & 7.95 & 0.00 & 6 \\
\hline lunar + time + rain + date + wind & 1025.22 & 8.60 & 0.00 & 7 \\
\hline Intercept & 1173.59 & 156.97 & 0.00 & 2 \\
\hline lunar+wind & 1188.31 & 171.69 & 0.00 & 4 \\
\hline lunar + rain + wind & 1188.35 & 171.73 & 0.00 & 5 \\
\hline lunar + date + wind & 1190.53 & 173.91 & 0.00 & 5 \\
\hline lunar + rain + wind + date & 1190.71 & 174.09 & 0.00 & 6 \\
\hline lunar+rain & 1193.21 & 176.59 & 0.00 & 4 \\
\hline lunar & 1193.64 & 177.02 & 0.00 & 3 \\
\hline lunar + rain + date & 1195.48 & 178.86 & 0.00 & 5 \\
\hline lunar+date & 1195.78 & 179.16 & 0.00 & 4 \\
\hline rain + wind + date & 1226.12 & 209.50 & 0.00 & 5 \\
\hline wind + date & 1226.97 & 210.35 & 0.00 & 4 \\
\hline rain + date & 1240.20 & 223.58 & 0.00 & 4 \\
\hline date & 1242.25 & 225.63 & 0.00 & 3 \\
\hline rain+wind & 1299.65 & 283.03 & 0.00 & 4 \\
\hline rain & 1336.47 & 319.85 & 0.00 & 3 \\
\hline
\end{tabular}

time $=$ time of day, rain $=$ rain during survey, date $=$ day-of-year, lunar $=\%$ lunar visibility/illumination, intercept $=$ null model . 
Table II. AICc table showing ranking of detection models for Eastern Whip-poor-will at boreal forest sites in northwestern Ontario. $\triangle \mathrm{AICc}=$ change in Akaike's Information Criteria corrected for small sample size, $w i=$ Akaike weights, $\mathrm{K}=$ number of model parameters.

\begin{tabular}{|c|c|c|c|c|}
\hline Detection & AICc & $\triangle \mathrm{AICc}$ & $\mathbf{W i}_{\mathbf{i}}$ & $\mathbf{K}$ \\
\hline time + rain & 419.37 & 0.00 & 0.28 & 4 \\
\hline time + rain + date & 420.18 & 0.81 & 0.19 & 5 \\
\hline time & 421.69 & 2.32 & 0.09 & 3 \\
\hline lunar+time + rain + date & 421.97 & 2.60 & 0.08 & 6 \\
\hline lunar + time + rain & 422.01 & 2.64 & 0.07 & 5 \\
\hline time + date & 422.09 & 2.72 & 0.07 & 4 \\
\hline time + rain + wind & 422.53 & 3.16 & 0.06 & 5 \\
\hline time + rain + wind + date & 423.52 & 4.15 & 0.03 & 6 \\
\hline lunar + time + date & 423.78 & 4.41 & 0.03 & 5 \\
\hline lunar+time & 424.20 & 4.83 & 0.02 & 4 \\
\hline time + wind & 424.44 & 5.07 & 0.02 & 4 \\
\hline time + wind + date & 425.00 & 5.63 & 0.02 & 5 \\
\hline lunar + time + rain + wind & 425.36 & 5.99 & 0.01 & 6 \\
\hline lunar + time + rain + date + wind & 425.48 & 6.11 & 0.01 & 7 \\
\hline lunar + time + wind + date & 426.48 & 7.11 & 0.01 & 6 \\
\hline lunar + time + wind & 426.93 & 7.56 & 0.01 & 5 \\
\hline intercept & 522.45 & 103.08 & 0.00 & 2 \\
\hline lunar+rain & 528.85 & 109.48 & 0.00 & 4 \\
\hline lunar + rain + date & 529.87 & 110.50 & 0.00 & 5 \\
\hline lunar + rain + wind & 530.60 & 111.23 & 0.00 & 5 \\
\hline lunar & 530.63 & 111.26 & 0.00 & 3 \\
\hline lunar+date & 531.41 & 112.04 & 0.00 & 4 \\
\hline lunar+wind & 531.69 & 112.32 & 0.00 & 4 \\
\hline lunar + rain + wind + date & 531.73 & 112.36 & 0.00 & 6 \\
\hline lunar + date + wind & 532.57 & 113.20 & 0.00 & 5 \\
\hline rain + date & 543.87 & 124.50 & 0.00 & 4 \\
\hline
\end{tabular}




$\begin{array}{llccc}\text { rain }+ \text { wind }+ \text { date } & 544.31 & 124.94 & 0.00 & 5 \\ \text { wind+date } & 545.19 & 125.82 & 0.00 & 4 \\ \text { date } & 545.84 & 126.47 & 0.00 & 3 \\ \text { rain }+ \text { wind } & 589.39 & 170.02 & 0.00 & 4 \\ \text { rain } & 598.01 & 178.64 & 0.00 & 3\end{array}$

time $=$ time of day, rain $=$ rain during survey, date $=$ day-of-year, lunar $=\%$ lunar visibility/illumination, intercept $=$ null model. 


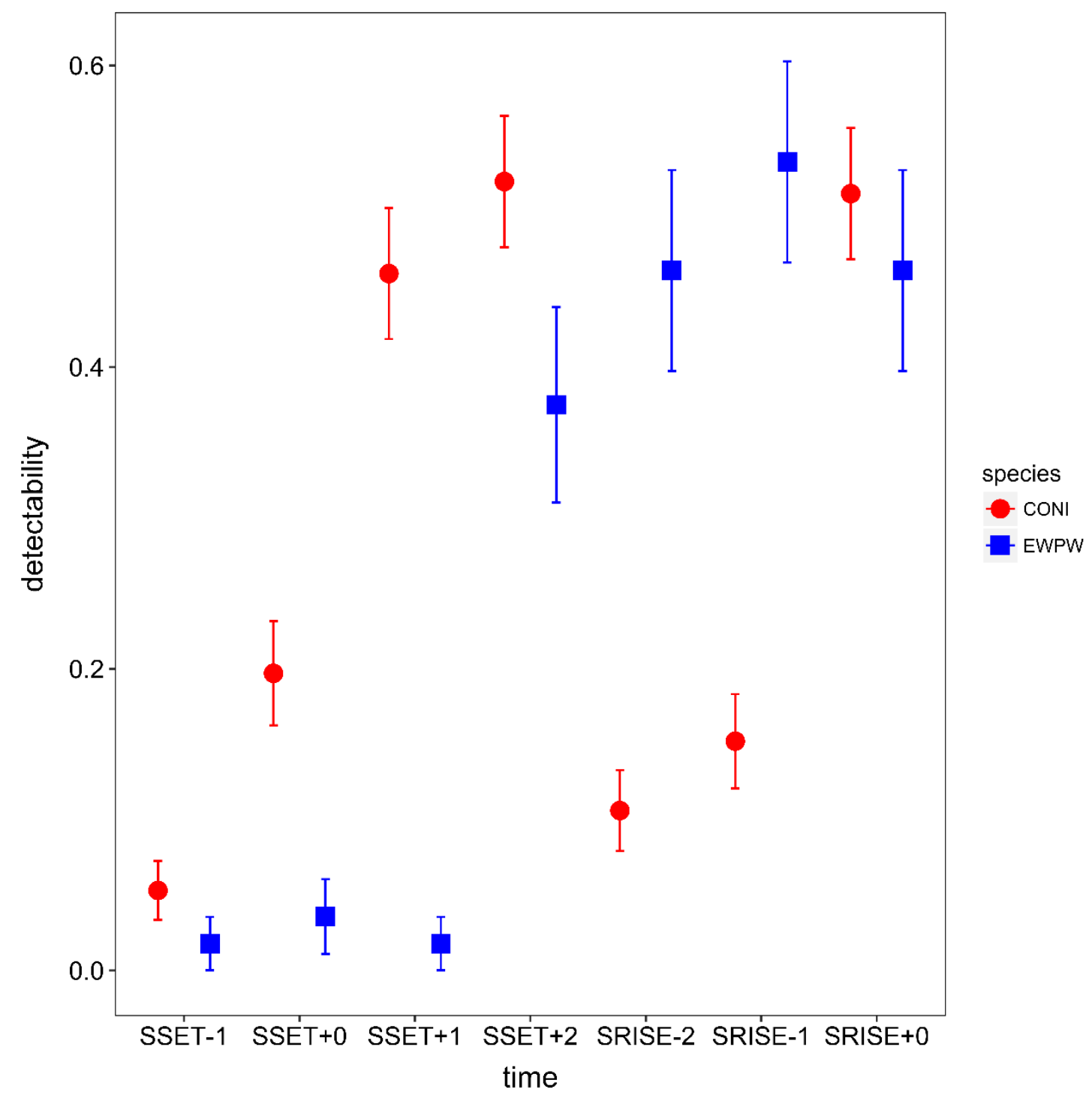

Fig. I. Mean detectability of Common Nighthawk and Eastern Whip-poor-will in Northwestern Ontario, Canada, May-July 2017, as a function of time of sampling (one hour before, at, and after sunset (SSET-1, SSET+0, SSET+1) as well as one and two hours after sunset (SSET+1, SSET+2). Two, and one hour(s) before sunrise as well as at sunrise (SSET-2, SSET-1, $\mathrm{SSET}+0)$ ). Error bars are $95 \%$ confidence intervals. 
Table III. Mean detectability based on time of sampling of Common Nighthawk and Eastern Whip-poor-will in Northwestern Ontario, Canada, May-July 2017. Times of sample are one hour before, at and after sunset (SSET-1, SSET+0, SSET+1) as well as one and two hours after sunset $(\mathrm{SSET}+1, \mathrm{SSET}+2)$, and two, and one hour(s) before sunrise as well as at sunrise (SSET-2, SSET-1, SSET+0)). Bold indicates significance of higher or lower mean detectability during that sampling time.

\begin{tabular}{|c|c|c|c|c|}
\hline & \multicolumn{2}{|c|}{ Common Nighthawk } & \multicolumn{2}{|c|}{ Eastern Whip-poor-will } \\
\hline Time & \multicolumn{2}{|c|}{ Detectability $S E$} & \multicolumn{2}{|c|}{ Detectability $S E$} \\
\hline SSET-1 & 0.05 & \pm 0.02 & 0.02 & \pm 0.02 \\
\hline $\mathrm{SSET}+0$ & 0.20 & \pm 0.03 & 0.04 & \pm 0.02 \\
\hline $\mathrm{SSET}+1$ & 0.46 & \pm 0.04 & 0.02 & \pm 0.02 \\
\hline $\mathrm{SSET}+2$ & 0.52 & \pm 0.04 & 0.38 & \pm 0.06 \\
\hline SRISE-2 & 0.11 & \pm 0.03 & 0.46 & \pm 0.07 \\
\hline SRISE-1 & 0.15 & \pm 0.03 & 0.54 & \pm 0.07 \\
\hline SRISE +0 & 0.52 & \pm 0.04 & 0.46 & \pm 0.07 \\
\hline
\end{tabular}




\section{APPENDIX II}

Mean Occupancy of Common Nighthawk (CONI) and Eastern Whip-poor-will (EWPW)

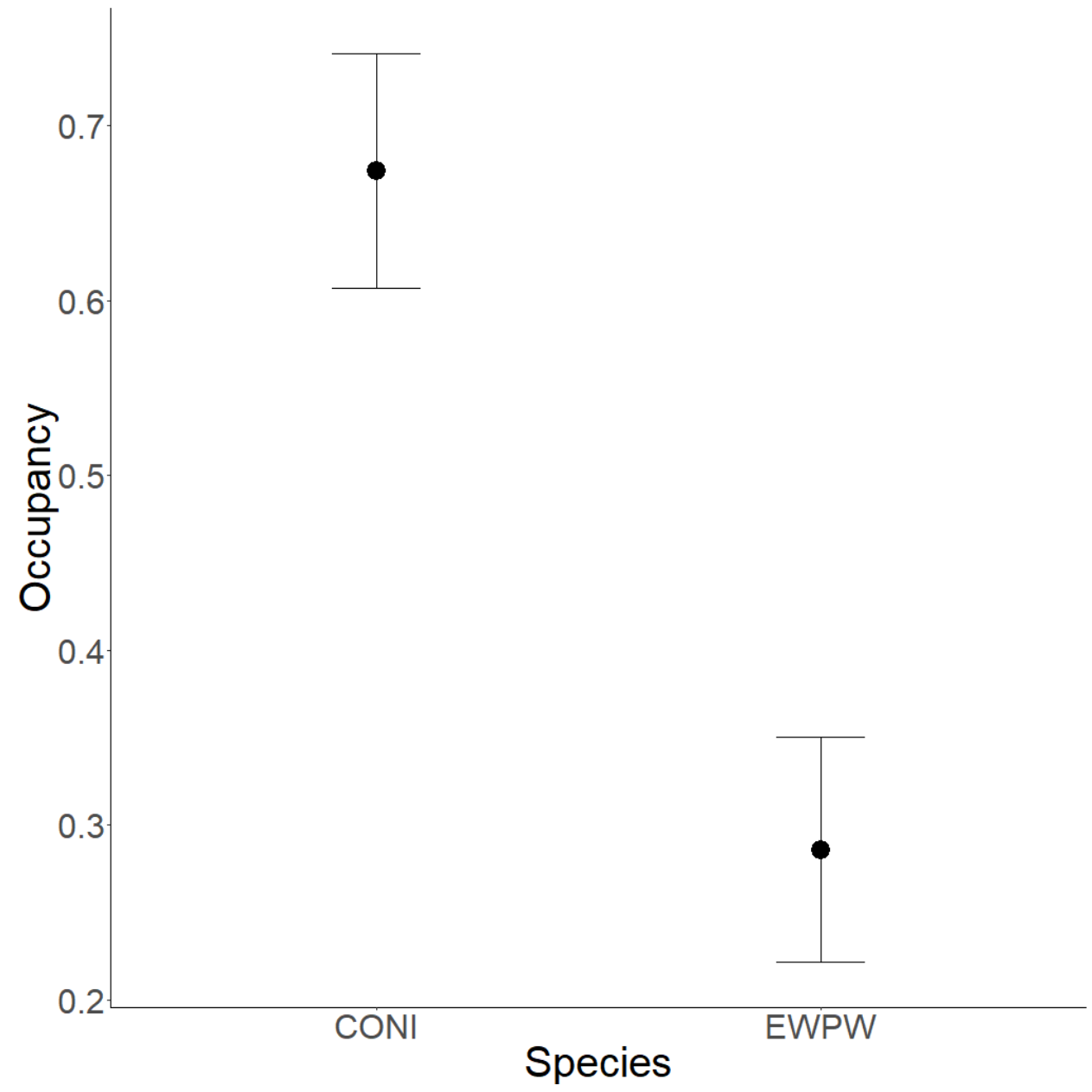

Fig. II. Mean site occupancy of Eastern Whip-poor-will (EWPW) and Common Nighthawk (CONI) in Northwestern Ontario, Canada, May-July 2017. Error bars are 95\% confidence intervals. 


\section{APPENDIX III}

\section{Open Wetland Scale of Effect Analysis}

Table IV. AICc and $\triangle \mathrm{AICc}$ values for open wetland scale of effect analysis for Common Nighthawk and Eastern Whip-poor-will. The direction of effect is indicated, and taken from the coefficient values, and shaded rows indicate scale of effect for Common Nighthawk $(1.5 \mathrm{~km})$ and Eastern Whip-poor-will $(5 \mathrm{~km})$. Significance is indicated with an $* *(p<0.05)$ or $* * *(p<0.01)$ at that spatial scale with $*$ indicating $\mathrm{p}<0.1$ but $>0.05$.

\begin{tabular}{|c|c|c|c|c|c|c|}
\hline & \multicolumn{3}{|c|}{ Common Nighthawk } & \multicolumn{3}{|c|}{ Eastern Whip-poor-will } \\
\hline $\begin{array}{l}\text { Scale } \\
(\mathrm{km})\end{array}$ & $\begin{array}{c}\text { Direction of } \\
\text { Effect }\end{array}$ & AICc & $\triangle \mathrm{AICc}$ & $\begin{array}{c}\text { Direction of } \\
\text { Effect }\end{array}$ & AICc & $\Delta \mathrm{AICc}$ \\
\hline 0.5 & + & 1018.69 & 4.62 & + & 422.10 & 14.47 \\
\hline 1 & + & $1016.07 *$ & 1.99 & + & 420.32 & 12.69 \\
\hline 1.5 & + & $1014.07 * *$ & 0.00 & + & $417.04 * *$ & 9.41 \\
\hline 2 & + & $1016.01 *$ & 1.94 & + & $413.79 * * *$ & 6.16 \\
\hline 2.5 & + & 1016.83 & 2.76 & + & $412.99 * * *$ & 5.36 \\
\hline 3 & + & 1017.09 & 3.01 & + & $411.88 * * *$ & 4.24 \\
\hline 3.5 & + & 1017.05 & 2.98 & + & $409.64 * * *$ & 2.01 \\
\hline 4 & + & 1016.98 & 2.91 & + & $408.41 * * *$ & 0.78 \\
\hline 4.5 & + & 1016.72 & 2.64 & + & $408.22 * * *$ & 0.59 \\
\hline 5 & + & $1016.40 *$ & 2.33 & + & $407.63 * * *$ & 0.00 \\
\hline
\end{tabular}




\section{APPENDIX IV}

\section{Total Clearcut Model Selection Analysis}

Table V. AICc table showing ranking of clearcut occupancy models for Common Nighthawk at boreal forest sites in northwestern Ontario. $\triangle \mathrm{AICc}=$ change in Akaike's Information Criteria corrected for small sample size, wi $=$ Akaike weights, $\mathrm{K}=$ number of model parameters.

\begin{tabular}{|c|c|c|c|c|c|}
\hline Detection & Occupancy & AICc & $\Delta \mathrm{AICc}$ & $\mathbf{w}_{\mathbf{i}}$ & $\mathbf{K}$ \\
\hline time & ForestType & 1010.99 & 0.00 & 0.26 & 4 \\
\hline time & ForestType+wetland_1500 & 1011.44 & 0.45 & 0.21 & 5 \\
\hline time & ForestType + CCUT_5km & 1012.42 & 1.43 & 0.13 & 5 \\
\hline time & ForestType $+E W P W$ & 1012.53 & 1.54 & 0.12 & 5 \\
\hline time & ForestType + age & 1013.84 & 2.85 & 0.06 & 5 \\
\hline time & ForestType + CCUT_5 $\mathrm{km}+$ wetland_1.5km & 1014.13 & 3.14 & 0.05 & 6 \\
\hline time & ForestType $+R S$ & 1014.13 & 3.14 & 0.05 & 5 \\
\hline time & ForestType + PatchArea & 1014.13 & 3.14 & 0.05 & 5 \\
\hline time & Intercept & 1016.62 & 5.63 & 0.02 & 3 \\
\hline time & CCUT_5km & 1018.14 & 7.15 & 0.01 & 4 \\
\hline time & CCUT_4.5km & 1018.27 & 7.28 & 0.01 & 4 \\
\hline time & CCUT_3km & 1018.68 & 7.69 & 0.01 & 4 \\
\hline time & CCUT_4km & 1018.70 & 7.71 & 0.01 & 4 \\
\hline time & CCUT_0.5km & 1018.71 & 7.72 & 0.01 & 4 \\
\hline time & CCUT_3.5km & 1018.77 & 7.78 & 0.01 & 4 \\
\hline time & CCUT_2.5km & 1018.91 & 7.92 & 0.00 & 4 \\
\hline time & CCUT_l $\mathrm{km}$ & 1019.20 & 8.21 & 0.00 & 4 \\
\hline time & CCUT_2km & 1019.42 & 8.43 & 0.00 & 4 \\
\hline time & CCUT_1.5km & 1019.64 & 8.65 & 0.00 & 4 \\
\hline intercept & intercept & 1173.59 & 162.6 & 0.00 & 2 \\
\hline
\end{tabular}

time = time of day, CCUT_Xkm = proportion of clearcut area within given radius, wetland_1.5km $=$ proportion of wetland area within $1.5 \mathrm{~km}$ radius, $E W P W=$ presence $/$ absence of Eastern Whippoor-will, PatchArea $=$ local clearcut patch area in $\mathrm{km}^{2}$, age $=$ age of local clearcut patch, $R S=$ 
presence/absence of Red Squirrel, ForestType = dominant tree type of old growth forest at edge of clearcut (i.e. coniferous/deciduous/mixed), intercept $=$ null model. 
Table VI. AICc table showing ranking of clearcut occupancy models for Eastern Whip-poor-will at boreal forest sites in northwestern Ontario. $\triangle \mathrm{AICc}=$ change in Akaike's Information Criteria corrected for small sample size, wi $=$ Akaike weights, $\mathrm{K}=$ number of model parameters.

\begin{tabular}{|c|c|c|c|c|c|}
\hline Detection & Occupancy & AICc & $\triangle \mathrm{AICc}$ & $\mathbf{w}_{\mathbf{i}}$ & $\mathbf{K}$ \\
\hline time + rain & wetland_5 km & 407.63 & 0.00 & 0.47 & 5 \\
\hline time+rain & wetland_5km + CCUT_5km & 410.80 & 3.17 & 0.10 & 6 \\
\hline time+rain & wetland_5km + CONI & 410.92 & 3.29 & 0.09 & 6 \\
\hline time+rain & wetland_5 $\mathrm{km}+$ age & 410.97 & 3.34 & 0.09 & 6 \\
\hline time + rain & wetland_5km + PatchArea & 410.98 & 3.35 & 0.09 & 6 \\
\hline time+rain & wetland_5km $+R S$ & 410.98 & 3.35 & 0.09 & 6 \\
\hline time+rain & wetland_5km + ForestType & 411.45 & 3.82 & 0.07 & 6 \\
\hline time + rain & CCUT_5km & 417.94 & 10.31 & 0.00 & 5 \\
\hline time+rain & CCUT_4.5km & 418.68 & 11.05 & 0.00 & 5 \\
\hline time + rain & intercept & 419.37 & 11.74 & 0.00 & 4 \\
\hline time + rain & CCUT_4km & 419.87 & 12.24 & 0.00 & 5 \\
\hline time + rain & CCUT_3.5m & 420.57 & 12.94 & 0.00 & 5 \\
\hline time + rain & CCUT_3km & 421.02 & 13.39 & 0.00 & 5 \\
\hline time+rain & CCUT_2.5km & 421.34 & 13.71 & 0.00 & 5 \\
\hline time + rain & CCUT_2km & 421.68 & 14.05 & 0.00 & 5 \\
\hline time + rain & CCUT_1.5km & 422.15 & 14.52 & 0.00 & 5 \\
\hline time+rain & CCUT_l $\mathrm{km}$ & 422.54 & 14.91 & 0.00 & 5 \\
\hline time + rain & CCUT_0.5km & 422.49 & 14.86 & 0.00 & 5 \\
\hline intercept & intercept & 522.45 & 114.82 & 0.00 & 2 \\
\hline
\end{tabular}

time = time of day, rain $=$ rain during survey, CCUT_Xkm = proportion of clearcut area within given radius, wetland_5 $\mathrm{km}=$ proportion of wetland area within $5 \mathrm{~km}$ radius, $C O N I=$ presence/absence of Common Nighthawk, PatchArea $=$ local clearcut patch area in $\mathrm{km}^{2}$, age $=$ age of local clearcut patch, $R S=$ presence/absence of Red Squirrel, ForestType $=$ dominant tree type of old growth forest at edge of clearcut (i.e. coniferous/deciduous/mixed), intercept $=$ null model. 
Table VII. Parameter estimates and standard errors for variables influencing detection and occupancy probability of Common Nighthawk and Eastern Whip-poor-will. Only variables that influenced probability for either of the two species are shown, with a "_" for cases where only one of the species was influenced by the variable.

\begin{tabular}{|c|c|c|c|c|c|c|}
\hline \multirow[b]{2}{*}{ Variable } & \multicolumn{3}{|c|}{ Eastern Whip-poor-will } & \multirow[b]{2}{*}{$\begin{array}{l}\text { Scale } \\
\text { of } \\
\text { Effect }\end{array}$} & \multicolumn{2}{|c|}{ Common Nighthawk } \\
\hline & $\begin{array}{c}\text { Scale } \\
\text { of } \\
\text { Effect }\end{array}$ & Estimate & $S E$ & & Estimate & $S E$ \\
\hline \multicolumn{7}{|l|}{ a) Detection Probability } \\
\hline time (SSET-1hr) & & $-3.97 * * *$ & 1.01 & & $-2.88 * * *$ & 0.39 \\
\hline time $(\mathrm{SSET}+0 \mathrm{hr})$ & & $-3.30 * * *$ & 0.72 & & $-1.41 * * *$ & 0.22 \\
\hline time (SSET+1hr) & & $-4.01 * * *$ & 1.01 & & -0.15 & 0.18 \\
\hline time (SSET+2hr) & & $-0.51 *$ & 0.28 & & 0.09 & 0.17 \\
\hline time (SRISE-2hr) & & 0.0002 & 0.28 & & $-2.13 * * *$ & 0.28 \\
\hline time (SRISE-1hr) & & 0.14 & 0.27 & & $-1.72 * * *$ & 0.24 \\
\hline time (SRISE+0hr) & & -0.14 & 0.27 & & 0.06 & 0.17 \\
\hline rain & & -9.67 & 62.58 & & - & - \\
\hline \multicolumn{7}{|l|}{ b) Occupancy Probability } \\
\hline Wetland & $5000 \mathrm{~m}$ & $29.94 * * *$ & 9.12 & $1500 \mathrm{~m}$ & 13.11 & 8.39 \\
\hline Clearcut & $5000 \mathrm{~m}$ & 2.71 & 6.47 & - & - & - \\
\hline Forest Type (coniferous) & & - & - & & $2.08 * * *$ & 0.75 \\
\hline Forest Type (deciduous) & & - & - & & -10.77 & 44.61 \\
\hline Forest Type (mixedwood) & & - & - & & $-1.64 *$ & 0.84 \\
\hline \multicolumn{7}{|c|}{$\begin{array}{l}\text { Wetland }=\text { proportion of open wetland, Clearcut }=\text { proportion of recent clearcut }(0-15 \text { years old), } \\
\text { Forest Type }=\text { categorical variable with forest type (coniferous) as intercept. } * \text { Indicates } \\
\text { significance of } \mathrm{p}<0.1, * * \text { significance of } \mathrm{p}<0.05 \text {, and } * * * \text { indicates significance of } \mathrm{p}<0.01 \text { for } \\
\text { parameters. Bold indicates parameter is present in top model. Non-bolded indicates parameter is } \\
\text { present in second best model. }\end{array}$} \\
\hline
\end{tabular}




\section{APPENDIX V}

\section{$\underline{\text { Age-specific Clearcut Model Selection Analysis }}$}

Table VIII. AICc table showing ranking of clearcut age class occupancy models for Common Nighthawk at boreal forest sites in northwestern Ontario. $\triangle \mathrm{AICc}=$ change in Akaike's Information Criteria corrected for small sample size, wi $=$ Akaike weights, $\mathrm{K}=$ number of model parameters.

\begin{tabular}{|c|c|c|c|c|c|}
\hline Detection & Occupancy & AICc & $\triangle \mathrm{AICc}$ & $\mathbf{W}_{\mathbf{i}}$ & $\mathbf{K}$ \\
\hline time & ForestType & 1010.99 & 0.00 & 0.97 & 4 \\
\hline time & CCUT_0-5 + CCUT_6-10 + CCUT_11-15+CCUT_16-20 $(0.5 \mathrm{~km})+$ ForestType & 1019.63 & 8.64 & 0.01 & 8 \\
\hline time & CCUT_0-5 + CCUT_6-10 + CCUT_11-15 + CCUT_16-20 $(0.5 \mathrm{~km})$ & 1021.48 & 10.49 & 0.01 & 7 \\
\hline time & CCUT_0-5 + CCUT_6-10 + CCUT_11-15 + CCUT_16-20 $(0.5 \mathrm{~km})+$ wetland_1.5km & 1021.63 & 10.64 & 0.00 & 8 \\
\hline time & CCUT_0-5 + CCUT_6-10+CCUT_11-15+CCUT_16-20 $(0.5 \mathrm{~km})+$ age & 1022.42 & 11.43 & 0.00 & 8 \\
\hline time & CCUT_0-5 + CCUT_6-10 + CCUT_11-15 + CCUT_16-20 (4.5km) & 1023.74 & 12.75 & 0.00 & 7 \\
\hline time & CCUT_0-5 + CCUT_6-10 + CCUT_11-15 + CCUT_16-20 $(1 \mathrm{~km})$ & 1023.76 & 12.77 & 0.00 & 7 \\
\hline time & CCUT_0-5 + CCUT_6-10+CCUT_11-15+CCUT_16-20 (0.5km) + EWPW & 1024.30 & 13.31 & 0.00 & 8 \\
\hline time & CCUT_0-5 + CCUT_6-10 + CCUT_11-15+CCUT_16-20 $(0.5 \mathrm{~km})+$ PatchArea & 1024.32 & 13.33 & 0.00 & 8 \\
\hline time & CCUT_0-5 + CCUT_6-10 + CCUT_11-15 + CCUT_16-20 (4km) & 1024.71 & 13.72 & 0.00 & 7 \\
\hline time & CCUT_0-5 + CCUT_6-10 + CCUT_11-15 + CCUT_16-20 $(0.5 \mathrm{~km})+R S$ & 1025.20 & 14.21 & 0.00 & 8 \\
\hline time & CCUT_0-5 + CCUT_6-10 + CCUT_11-15 + CCUT_16-20 (3km) & 1025.45 & 14.46 & 0.00 & 7 \\
\hline time & CCUT_0-5 + CCUT_6-10 + CCUT_11-15 + CCUT_16-20 (3.5km) & 1025.66 & 14.67 & 0.00 & 7 \\
\hline time & CCUT_0-5 + CCUT_6-10 + CCUT_11-15 + CCUT_16-20 (1.5km) & 1025.79 & 14.8 & 0.00 & 7 \\
\hline time & CCUT_0-5 + CCUT_6-10 + CCUT_11-15 + CCUT_16-20 $(2.5 \mathrm{~km})$ & 1025.89 & 14.9 & 0.00 & 7 \\
\hline time & CCUT_0-5 + CCUT_6-10 + CCUT_11-15 + CCUT_16-20 (2km) & 1026.21 & 15.22 & 0.00 & 7 \\
\hline time & CCUT_0-5 + CCUT_6-10 + CCUT_11-15 + CCUT_16-20 (5km) & 1026.91 & 15.92 & 0.00 & 7 \\
\hline intercept & intercept & 1173.59 & 162.6 & 0.00 & 2 \\
\hline
\end{tabular}

time $=$ time of day, ForestType $=$ dominant tree type of old growth forest at edge of clearcut (i.e. coniferous/deciduous/mixed), CCUT_0-5/6-10/11-15/16-20 $(\mathrm{Xkm})=$ proportion of clearcut area of a given age class $(0-5,6-10,11-15,16-20$ years old) within given radius $(\mathrm{Xkm})$, wetland $1.5 \mathrm{~km}=$ proportion of wetland area within $1.5 \mathrm{~km}$ radius, age $=$ age of local clearcut 
patch, $E W P W=$ presence/absence of Eastern Whip-poor-will, PatchArea $=$ local clearcut patch area in $\mathrm{km} 2, R S=$ presence/absence of Red Squirrel, intercept $=$ null model. 
Table IX. AICc table showing ranking of clearcut age class occupancy models for Eastern Whip-poor-will at boreal forest sites in northwestern Ontario. $\triangle \mathrm{AICc}=$ change in Akaike's Information Criteria corrected for small sample size, wi $=$ Akaike weights, $\mathrm{K}=$ number of model parameters.

\begin{tabular}{|c|c|c|c|c|c|}
\hline Detection & Occupancy & AICc & $\triangle \mathrm{AICc}$ & $\mathbf{w}_{\mathbf{i}}$ & $\mathbf{K}$ \\
\hline time + rain & wetland_5km & 407.63 & 0.00 & 1.00 & 5 \\
\hline time + rain & CCUT_0-5 + CCUT_6-10 + CCUT_11-15 + CCUT_16-20 (5km) + wetland_5km & 419.57 & 11.74 & 0.00 & 9 \\
\hline time + rain & CCUT_0-5 + CCUT_6-10 + CCUT_11-15 + CCUT_16-20 (5km) & 422.47 & 14.84 & 0.00 & 8 \\
\hline time + rain & CCUT_0-5 + CCUT_6-10 + CCUT_11-15 + CCUT_16-20 (4.5km) & 424.15 & 16.52 & 0.00 & 8 \\
\hline time + rain & CCUT_0-5 + CCUT_6-10 + CCUT_11-15+CCUT_16-20 (5km) + RS & 424.45 & 16.82 & 0.00 & 9 \\
\hline time + rain & CCUT_0-5 + CCUT_6-10 + CCUT_11-15 + CCUT_16-20 (5km) + CONI & 424.78 & 17.15 & 0.00 & 9 \\
\hline time + rain & CCUT_0-5 + CCUT_6-10 + CCUT_11-15 + CCUT_16-20 $(5 \mathrm{~km})+$ PatchArea & 426.09 & 18.46 & 0.00 & 9 \\
\hline time + rain & CCUT_0-5 + CCUT_6-10 + CCUT_11-15 + CCUT_16-20 (4km) & 426.28 & 18.65 & 0.00 & 8 \\
\hline time+rain & CCUT_0-5 + CCUT_6-10 + CCUT_11-15 + CCUT_16-20 (5km) + age & 426.41 & 18.78 & 0.00 & 9 \\
\hline time + rain & CCUT_0-5 + CCUT_6-10 + CCUT_11-15 + CCUT_16-20 (3.5km) & 427.39 & 19.76 & 0.00 & 8 \\
\hline time+rain & CCUT_0-5 + CCUT_6-10 + CCUT_11-15 + CCUT_16-20 (3km) & 427.44 & 19.81 & 0.00 & 8 \\
\hline time + rain & CCUT_0-5 + CCUT_6-10 + CCUT_11-15 + CCUT_16-20 (2.5km) & 428.90 & 21.27 & 0.00 & 8 \\
\hline time + rain & CCUT_0-5 + CCUT_6-10 + CCUT_11-15 + CCUT_16-20 (2km) & 430.70 & 23.07 & 0.00 & 8 \\
\hline time + rain & CCUT_0-5 + CCUT_6-10 + CCUT_11-15 + CCUT_16-20 $(1.5 \mathrm{~km})$ & 431.98 & 24.35 & 0.00 & 8 \\
\hline time + rain & CCUT_0-5 + CCUT_6-10 + CCUT_11-15 + CCUT_16-20 $(1 \mathrm{~km})$ & 432.32 & 24.69 & 0.00 & 8 \\
\hline time+rain & CCUT_0-5 + CCUT_6-10 + CCUT_11-15 + CCUT_16-20 $(0.5 \mathrm{~km})$ & 430.47 & 22.84 & 0.00 & 8 \\
\hline time + rain & CCUT_0-5 + CCUT_6-10 + CCUT_11-15 + CCUT_16-20 (5km) + ForestType & 430.66 & 23.03 & 0.00 & 9 \\
\hline intercept & intercept & 522.45 & 114.82 & 0.00 & 2 \\
\hline \multicolumn{6}{|c|}{$\begin{array}{l}\text { time }=\text { time of day, rain }=\text { rain during sample, wetland_5 } \mathrm{km}=\text { proportion of wetland area within } \\
5 \mathrm{~km} \text { radius, CCUT_0-5/6-10/11-15/16-20 }(\mathrm{Xkm})=\text { proportion of clearcut area of a given age } \\
\text { class }(0-5,6-10,11-15,16-20 \text { years old) within given radius }(\mathrm{Xkm}), R S=\text { presence/absence of } \\
\text { red squirrel, } C O N I=\text { presence } / \text { absence of Common Nighthawk, PatchArea }=\text { local clearcut } \\
\text { patch area in } \mathrm{km}^{2}, \text { age }=\text { age of local clearcut patch, ForestType }=\text { dominant tree type of old } \\
\text { growth forest at edge of clearcut (i.e. coniferous/deciduous } / \text { mixed), intercept }=\text { null model. }\end{array}$} \\
\hline
\end{tabular}


Table X. AICc table showing top models of total clearcut and age-specific occupancy model analysis for Common Nighthawk and Eastern Whip-poor-will at boreal forest sites in northwestern Ontario. Top detection variables for Common Nighthawk (time) and Eastern Whippoor-will (time+rain) were included in models but are not shown. $\triangle \mathrm{AICc}=$ change in Akaike's Information Criteria corrected for small sample size, wi $=$ Akaike weights, $\mathrm{K}=$ number of model parameters.

\begin{tabular}{|c|c|c|c|c|c|c|c|c|c|}
\hline \multicolumn{5}{|c|}{ Common Nighthawk } & \multicolumn{5}{|c|}{ Eastern Whip-poor-will } \\
\hline Model & AICc & $\triangle \mathrm{AICc}$ & $\mathbf{W i}$ & $\mathbf{K}$ & Model & AICc & $\triangle \mathrm{AICc}$ & $\mathbf{W i}$ & $\mathbf{K}$ \\
\hline ForestType + CCUT_11-15(0.5km) & 1009.99 & 0.00 & 0.07 & 5 & wetland_5 km & 407.63 & 0.00 & 0.47 & 5 \\
\hline ForestType & 1010.99 & 1.00 & 0.04 & 4 & wetland_5 $\mathrm{km}+$ CCUT_6-10(5km) & 409.55 & 1.92 & 0.18 & 6 \\
\hline ForestType + CCUT_0-5 $(0.5 \mathrm{~km})$ & 1012.94 & 2.95 & 0.30 & 5 & wetland_5 $\mathrm{km}+$ CCUT_0-5 $(5 \mathrm{~km})$ & 409.67 & 2.04 & 0.17 & 6 \\
\hline ForestType + CCUT_16-20(0.5km) & 1013.88 & 3.89 & 0.01 & 5 & wetland_5km + CCUT_11-15(5km) & 410.82 & 3.19 & 0.10 & 6 \\
\hline ForestType + CCUT_6-10 $(0.5 \mathrm{~km})$ & 1014.20 & 4.21 & 0.5 & 5 & wetland_5 $5 \mathrm{~km}+$ CCUT_16-20(5km) & 410.97 & 3.34 & 0.09 & 6 \\
\hline
\end{tabular}

ForestType $=$ dominant tree type of old growth forest at edge of clearcut (i.e.

coniferous/deciduous/mixed), wetland_X $\mathrm{km}=$ proportion of wetland area within a given $\mathrm{km}$ radius, $C C U T \_5 \mathrm{~km}=$ proportion of total clearcut area (0-15 years old), CCUT_0-5/6-10/11$15 / 16-20(X \mathrm{~km})=$ proportion of clearcut area of a given age class $(0-5,6-10,11-15,16-20$ years old) within given radius $(\mathrm{Xkm})$, 


\section{APPENDIX VI}

Farrell et al. (2017) Habitat Associations of Common Nighthawk and Eastern Whip-poorwill

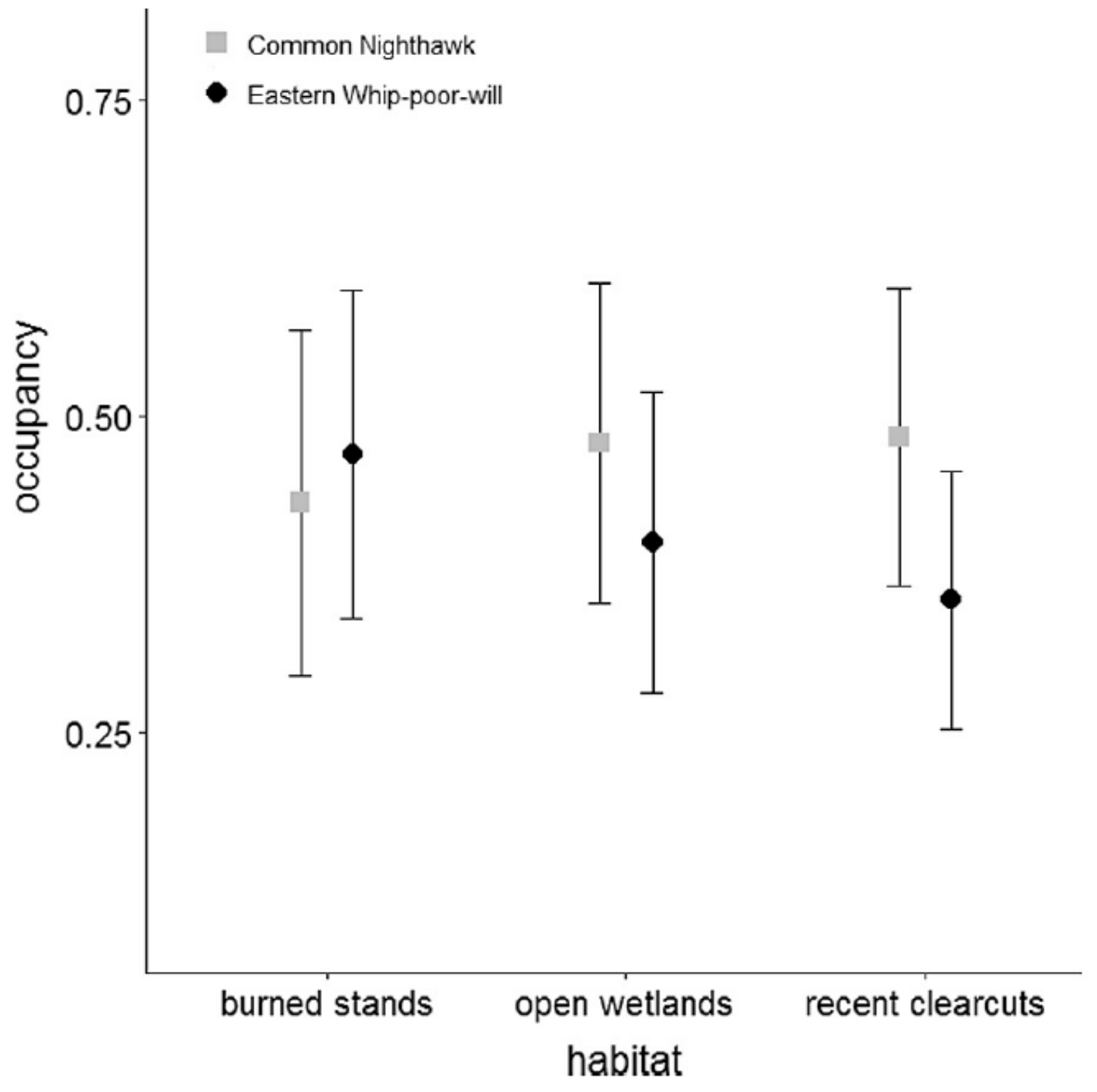

Fig. III. Mean site occupancy of Eastern Whip-poor-wills and Common Nighthawks in Northwestern Ontario, Canada, May-July 2015, as a function of habitat type. Shown are expectations from the top model. Error bars are 95\% confidence intervals. Unlike Common Nighthawk that showed very similar occupancy across all three habitat types, Eastern Whippoor-will showed a slight preference for burned stands $(0.470 \pm 0.130)$ as compared to open wetlands $(0.400 \pm 0.119)$ and clearcuts $(0.355 \pm 0.102)$ (Farrell et al. 2017). 


\section{APPENDIX VII}

$\underline{\text { Regional Effect on Proportion of Open Wetland }}$

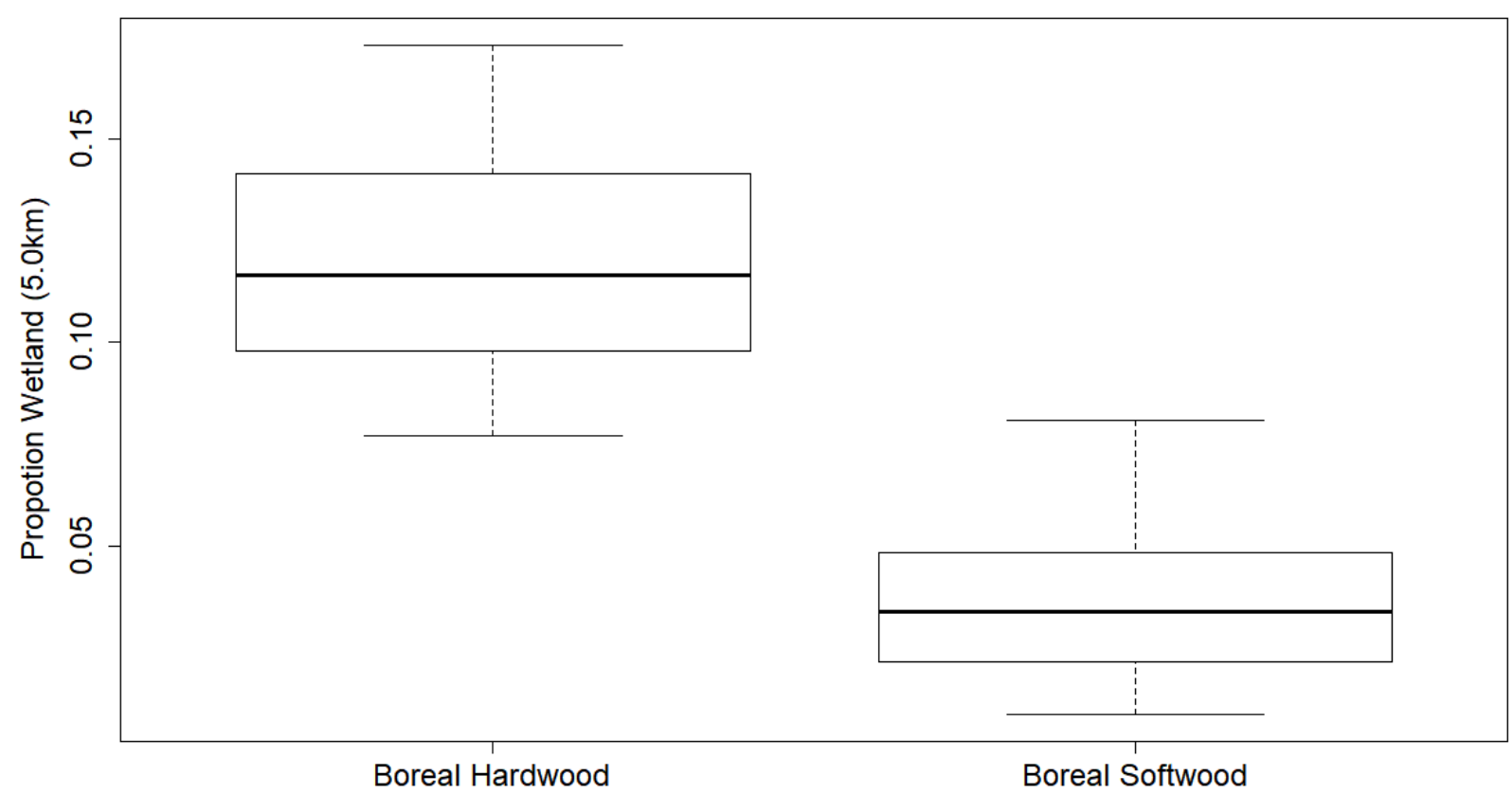

Fig. IV. Graph demonstrating higher proportion of open wetland area in $5.0 \mathrm{~km}$ radius landscapes in the Boreal Hardwood Transition and Boreal Softwood Shield bird conservation regions (Environment Canada 2014a; Environment Canada 2014b). Dark black lines represent the mean, whisker brackets represent $95 \%$ confidence intervals. 


\section{APPENDIX VII}

\section{Diversity of open wetlands in study area}

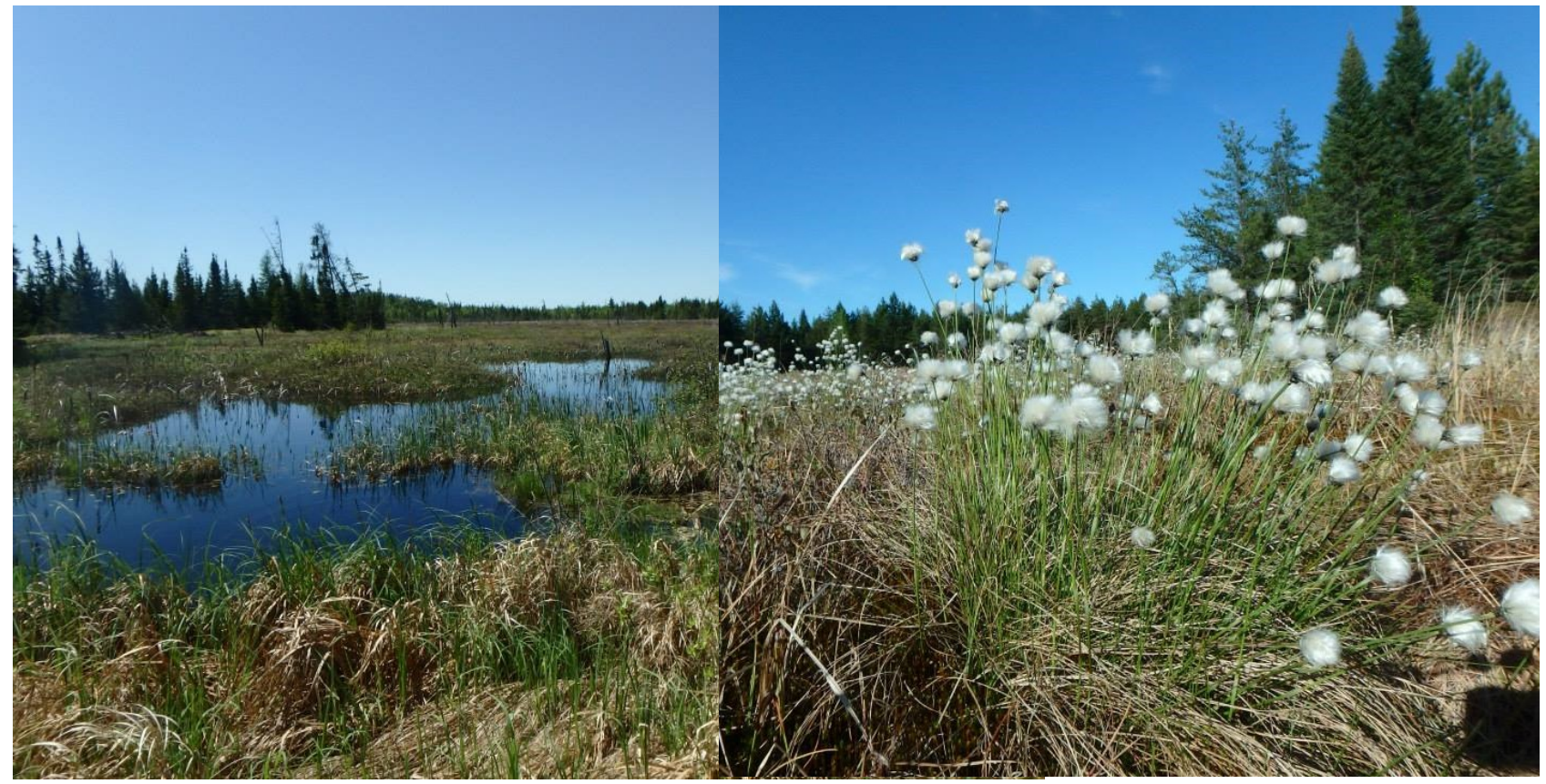

Fig V. The image on the left shows an open wetland in my study area that represents wetlands that can be wet or aquatic in nature. However, the image on the right represents a different wetland that is ephemerally dry in my study area. My research demonstrates both species respond positively to wetland on a landscape scale despite some literature stating their lack of value as habitat for Eastern Whip-poor-will (Batzer and Wissinger 1996; Cink 2002) and more recent literature from Rand (2014) stating wetland are avoided by Eastern Whip-poor-will.

Furthermore, I note that in my study I made sure to only select open wetlands using the classification of "open" as defined in the Forest Resource Inventory spatial metadata (OMNRF 2017). I did this to, as accurately as possible, make sure that the wetlands I was measuring were viable habitat for the species (i.e. open habitat where the species would be able to forage without difficulty). It is unclear whether Rand (2014) who found a negative effect of wetlands on Eastern Whip-poor-will, measured all wetlands, or only open wetlands as I did here. This, and my larger sample size, could explain the difference in direction of effect of wetlands for my and Rand's (2014) study. 